\title{
Inflammatory Mechanisms of Neurodegeneration in Toxin-Based Models of Parkinson's Disease
}

\author{
Darcy Litteljohn, Emily Mangano, Melanie Clarke, Jessica Bobyn, Kerry Moloney, \\ and Shawn Hayley
}

Institute of Neuroscience, Carleton University, 1125 Colonel By Drive, Ottawa, ON, Canada K1S 5B6

Correspondence should be addressed to Shawn Hayley, shayley@connect.carleton.ca

Received 15 October 2010; Accepted 9 December 2010

Academic Editor: Stéphane Hunot

Copyright $\odot 2011$ Darcy Litteljohn et al. This is an open access article distributed under the Creative Commons Attribution License, which permits unrestricted use, distribution, and reproduction in any medium, provided the original work is properly cited.

Parkinson's disease (PD) has been associated with exposure to a variety of environmental agents, including pesticides, heavy metals, and organic pollutants; and inflammatory processes appear to constitute a common mechanistic link among these insults. Indeed, toxin exposure has been repeatedly demonstrated to induce the release of oxidative and inflammatory factors from immunocompetent microglia, leading to damage and death of midbrain dopamine (DA) neurons. In particular, proinflammatory cytokines such as tumor necrosis factor- $\alpha$ and interferon- $\gamma$, which are produced locally within the brain by microglia, have been implicated in the loss of DA neurons in toxin-based models of PD; and mounting evidence suggests a contributory role of the inflammatory enzyme, cyclooxygenase-2. Likewise, immune-activating bacterial and viral agents were reported to have neurodegenerative effects themselves and to augment the deleterious impact of chemical toxins upon DA neurons. The present paper will focus upon the evidence linking microglia and their inflammatory processes to the death of DA neurons following toxin exposure. Particular attention will be devoted to the possibility that environmental toxins can activate microglia, resulting in these cells adopting a "sensitized" state that favors the production of proinflammatory cytokines and damaging oxidative radicals.

\section{Introduction}

Parkinson's disease (PD) is the most common neurodegenerative disorder of motor functioning, affecting nearly six million people worldwide. The disorder is particularly prevalent in the elderly population, with a typical clinical onset after 60-65 years of age. Notwithstanding the rare familial forms of PD that appear to have a strong genetic component, the vast majority of PD cases (upwards of 90\%) are idiopathic in nature. Regardless of etiology, PD is characterized primarily by the progressive degeneration of dopamine (DA) neurons within the substantia nigra pars compacta $(\mathrm{SNc})$ region of the midbrain, resulting in the diminished monoamine release at downstream striatal nerve terminals. Clinically, the Parkinsonian syndrome, which typically becomes manifest following 50-60\% SNc DA neuron loss, comprises a constellation of well-defined motor symptoms, including bradykinesia, hypokinesia (or akinesia), cogwheel rigidity, resting tremor, and postural instability [1]. In addition to the motor impairment evident in all PD cases, a substantial number of PD patients also display prominent "nonmotor" symptoms (many of which manifest before the onset of motor decline and PD diagnosis), including autonomic and olfactory problems (e.g., sleep disorders, hyposmia), as well as cognitive and psychological disturbances (e.g., anxiety, depression) [2]. While striatal DA denervation may influence the development of at least some of these symptoms (e.g., memory and attention problems [3]), it is likely that multineurotransmitter dysfunction in brain regions important for autonomic, emotional and psychological functioning (e.g., locus coeruleus, prefrontal cortex, hippocampus) is important in this regard (perhaps stemming from parallel inflammatory and neurodegenerative processes) $[4,5]$.

Epidemiological studies have implicated exposure to pesticides and other potential environmental toxins (e.g., heavy metals and even immune infections) in the evolution of PD $[6,7]$. Parallel work in rodents has likewise revealed that administration of certain pesticides, most notably 
paraquat and rotenone, recapitulates many of the characteristic neuropathological and behavioral features of $\operatorname{PD}[8,9]$. Over the past few decades it has become clear that neuroinflammatory factors, including proinflammatory cytokines produced by glial cells, are involved in many aspects of the neurodegenerative process in PD. Indeed, manipulation of cytokines and associated inflammatory signaling pathways was reported to affect DA neuronal survival in response to a host of different toxins $[10,11]$. Moreover, alterations of microglial cell reactivity have been routinely demonstrated during early and late phases of the degenerative process in animal models of PD [12,13]. Correspondingly, postmortem PD brains typically display signs of heightened inflammatory and oxidative distress, including increased proinflammatory cytokines and microglial activation $[14,15]$, as well as augmented oxidative and inflammatory enzyme expression (e.g., nicotinamide adenine dinucleotide phosphate (NADPH) oxidase, inducible nitric oxide synthase (iNOS), cyclooxygenase-2 (COX-2)) [16, 17].

Substantial recent interest has focused on microglial cells as potential mediators of pathology in PD; however, it remains to be determined whether these cells are primary players in disease progression or are secondarily recruited following damage. Alternatively, it might be the case that microglia are involved in all stages of PD but that their role changes (e.g., neuroprotective versus neurodestructive) as the disease progresses through different stages. Indeed, during normal physiological conditions microglial cells are constantly detecting and reacting to modifications in their local environment and attempting to maintain proper tissue homeostasis $[18,19]$. When sufficiently stressed by insults, neurons release ATP into the extracellular space and microglia migrate along these ATP gradients and facilitate the removal of the dead/sick cells through phagocytosis $[18,20]$. However, in the case of PD, these "danger" signals released from injured and dying cells (e.g., ATP, heat-shock proteins) may be subtle and occur over a prolonged period of time [21], essentially placing microglia in a chronically active state.

The reactivity state of microglia varies along a spectrum ranging from resting to hyperactive and is under the strict control of several regulatory proteins [22]. Some evidence suggests that microglial cells can perform neuroprotective functions in PD, at least in the short term, by secreting trophic factors such as nerve growth factor, neurotrophin3 and brain-derived neurotrophic factors (BDNFs) [23, 24]. However, as the disease progresses, there is compelling evidence to indicate that microglia undergo significant elevations in cell surface activation/adhesion molecules and adopt a more hyperactive state that is morphologically similar to peripheral macrophages [25]. In this state, microglia are capable of upregulating the synthesis and release of a host of proinflammatory and prooxidant factors, including cytokines, prostaglandins (PGs) and reactive oxygen species (ROS) [26]. Indeed, following toxin exposure, chronically activated microglia can produce large quantities of superoxide (e.g., via the NADPH oxidase enzyme), which, in turn, can lead to the damage and death of adjacent DA neurons $[27,28]$.
The present paper will, (1) cover the evidence linking exposure to environmental toxins and the development of PD; (2) review the mechanisms by which inflammatory cytokines affect central nervous system (CNS) functioning; and (3) evaluate the possibility that cytokines and inflammatory and oxidative enzymes are involved in the PD-like neurodegenerative process induced by environmental toxins.

\section{Environmental Toxin Exposure and PD}

Although familial forms of PD are relatively rare, certain genetic mutations have been reported to enhance susceptibly to environmental insults and hence, might contribute to the more common idiopathic cases of the disease. In fact, a recent study revealed that individuals possessing a combination of mutations of the DA transporter (DAT) and who had substantial life-long pesticide exposure were at greater risk for developing PD than individuals with either the genetic factor or pesticide exposure alone [6]. Moreover, the recent findings that polymorphism within certain environment responsive genes encoding effector proteins critical for cellular detoxification and xenobiotic metabolism (e.g., CYP2D64, GSTT1 and P1) modified the risk of developing $\mathrm{PD}$, suggests that environmental toxicants might contribute to PD in genetically vulnerable individuals $[29,30]$. However, another report indicated that pesticide exposure was a significant predictor of PD incidence among individuals with a negative family history but not those with a positive family history of the disease [31]. In effect, it is likely that the role of genetics depends upon the particular "subtype" of PD. Indeed, PD appears to be a highly heterogeneous disorder with corresponding heterogeneity in etiological origins. Whereas autosomal dominant/recessive familial forms of PD (e.g., LRRK2, DJ-1, Parkin) appear to be at one end of the spectrum, purely environmental "toxic exposure" cases may represent the other end. Hence, the bulk of "idiopathic" PD cases falls in the middle and will likely involve a mix of genetic and environmental influences. Indeed, there is a very low penetrance of LRRK2 heterozygotic carriers that actually express the PD phenotype; yet, a significant proportion of PD patients carry a LRRK2 mutation, suggesting that such genes might be seen as susceptibility factors [32].

While genetic vulnerability may be seen as providing a backdrop for disease provocation, several compelling lines of evidence suggest that environmental agents, including commonly used pesticides, can act as triggers for the development of PD. In fact, a progressively greater odds ratio for developing PD was associated with pesticide exposure [6], and several other epidemiological studies have implicated specific pesticides, including rotenone (an organic insecticide) and paraquat (a chemical herbicide still widely used throughout the world), in the development of parkinsonism $[33,34]$. Indeed, a sharp increase of PD incidence was seen in agricultural areas that use these pesticides $[35,36]$. In particular, the nonselective herbicide, paraquat $\left(\mathrm{N}, \mathrm{N}^{\prime}\right.$ dimethyl-4,4' -bipyridylium ion), significantly augmented the risk of developing $\mathrm{PD}$ as a function of cumulative pesticide exposure [37]. 
Animal studies also demonstrate that the pesticides, paraquat and rotenone, which are chemically similar to the established DA neurotoxin, MPTP, can reliably induce PD-like pathology, and hence, are becoming widely used to produce a parkinsonian syndrome in animals. Indeed, systemic exposure to paraquat provoked a dose-dependent loss of DA neurons in the SNc $[8,38]$, coupled with a reduction in the density of striatal DA fibres expressing tyrosine hydroxylase, the rate-limiting enzyme in DA synthesis [39]. The pesticide was also shown to diminish striatal DA concentration and to reproduce certain aspects of the PD phenotype in rodents (bradykinesia, motor coordination deficits, depressive-like symptoms, memory impairment) [39-43]. However, it is worth noting that the impact of paraquat upon the striatum appears to be somewhat less pronounced than the effects of the pesticide upon SNc DA neuronal soma [44]. As well, some authors have failed to find changes in striatal DA levels or behavioral impairment, even in the presence of loss of DA soma [45]. It is conceivable that compensatory downstream processes provoked by soma loss (e.g., changes in dendritic branching patterns, upregulation of proneuroplastic peptides or neurotrophins, or alterations of brain monoamine systems) could account for such discrepancies between SNc pathology and striatal functioning. Also, variations in experimental design (e.g., route of administration, dosing regimen, sacrifice interval, striatal subregions tested, age of mice) probably contribute to some of the inconsistency in findings across studies [46-48].

Of course, paraquat is not alone in producing sometimes discrepant research findings, as virtually all of the most common toxin models of PD have engendered controversy with respect to selective DA neuron loss, variable striatal DA depletion and behavioral impairment, and/or the generation of Lewy body-like $\alpha$-synuclein inclusions (see Table 1) [4951]. Of these PD mimetics, MPTP is perhaps the most widely used and well characterized, producing consistent and reproducible PD-like pathology in several animal species (e.g., DA lesion, reactive microgliosis, motor deficit). Yet, pesticides such as paraquat and rotenone, in addition to having greater ecological relevance than the MPTP model of $\mathrm{PD}$, have been shown to provoke histopathological changes that more closely resemble the disease, particularly the deposition of $\alpha$-synuclein aggregates in neuronal Lewy bodylike inclusions (see Table 1) $[9,52,53]$. In fact, Drolet and colleagues [54] recently found that rats treated with systemic rotenone displayed marked $\alpha$-synuclein pathology in small intestine myenteric neurons that was reminiscent of the enteric Lewy body pathology commonly seen in PD patients. Moreover, it was reported that exposure to certain combinations of heavy metals and pesticides may synergistically provoke conformational changes in $\alpha$ synuclein, favoring the development of PD-like pathology [55]. In fact, recent work revealed that exposure to a combination of iron and paraquat synergistically increased $\alpha$-synuclein aggregation and fibrillization, and augmented the extent of microglia-induced oxidative stress and neurodegeneration $[56,57]$. Similarly, although the dithiocarbamate pesticide, maneb, had no effect on SNc DA neurons alone, when coadministered with paraquat it synergistically enhanced nigrostriatal damage and associated glial reactivity [58].

Pesticides can adversely affect neuronal survival by impairing mitochondrial functioning and overstimulating microglial cells, causing an accumulation of oxidative free radicals (e.g., superoxide, hydroxyl radicals) and inflammatory factors (particularly cytokines). Indeed, as will be discussed in ensuing sections, we and others showed that paraquat and rotenone enhanced the expression of proinflammatory cytokines and elicited oxidative-nitrosative stress through activation of the microglial inflammatory enzyme, NADPH oxidase. In fact, as was reported for MPTP [27], paraquat was demonstrated to preferentially damage midbrain DA neurons through direct microglial-dependent NADPH oxidase activity in neuron-microglia cultures [59]. However, the role of microglia is not without controversy, with one recent report indicating that neither rotenone nor paraquat directly activated cultured microglia (in terms of morphology, nitric oxide synthesis and cytokine release) [60]. Similarly, accumulating evidence suggests that the PG synthase, COX-2, may contribute to the neurodegenerative effects of numerous DA toxins.

\section{Inflammatory Cytokines in Relation to Central Nervous System Functioning}

Until fairly recently the brain was believed to function more or less independently of the immune system. However, it is now accepted that circulating $\mathrm{T}$ lymphocytes, macrophages and other peripheral immune cells routinely enter cerebrum, albeit in limited concentrations, and perform a variety of "housekeeping" tasks that are essential for immunosurveillance of the CNS [61]. The converse is also true in that changes in neural transmission, such as those provoked by drug administration, can affect immune cell activity in the periphery. Yet, it should be noted that the blood brain barrier (BBB), as well as several endogenous inhibitory and apoptotic mechanisms operating within the brain itself, normally tightly regulate the transmigratory flow of immune factors into the CNS, and how long they persist therein. For instance, immune cells entering the brain typically are removed or die via apoptosis relatively rapidly; this is essential since postmitotic neurons are especially sensitive to immune attack. However, increasing evidence indicates that a range of neurological diseases, including Amyotrophic Lateral Sclerosis, Alzheimer's disease $(\mathrm{AD})$ and $\mathrm{PD}$ have a prominent neuroinflammatory component, involving increased infiltration of immune cells, coupled with activation of resident brain glial cells $[17,62]$.

Nonetheless, it should be underscored that not all CNS inflammation is uniformly "bad"; indeed, transient neuroinflammatory responses are a natural consequence of injury or infection and may actually preserve viable brain tissue in a manner analogous to a short-lived immune response in the periphery (e.g., removal of cellular debris, release of trophic factors) [63, 64]. Moreover, neuronal degeneration itself provokes secondary inflammation that may or may not 
TABLe 1: A comparison of some of the most common toxin-based animal models of Parkinson's disease.

\begin{tabular}{|c|c|c|c|}
\hline $\begin{array}{l}\text { Toxin } \\
\text { model }\end{array}$ & Mode of action & Advantages & Disadvantages \\
\hline 6-OHDA & $\begin{array}{l}\text { (i) DAT substrate } \\
\text { (ii) Cytotoxic quinone and ROS } \\
\text { formation }\end{array}$ & $\begin{array}{l}\text { (i) Full DA depletion } \\
\text { (ii) Mimics late-stage PD }\end{array}$ & $\begin{array}{l}\text { (i) Does not cross BBB } \\
\text { (ii) DA degeneration is not progressive } \\
\text { (iii) No Lewy body-like inclusions } \\
\text { (iv) Lacks external validity }\end{array}$ \\
\hline MPTP & $\begin{array}{l}\text { (i) Converted into } \mathrm{MPP}^{+} \\
\text {(ii) DAT substrate } \\
\text { (iii) Inhibits mitochondrial complex I } \\
\text { (iv) Strong inflammatory component }\end{array}$ & $\begin{array}{l}\text { (i) Highly reproducible } \\
\text { (ii) Induces substantial DA loss and } \\
\text { motor impairment }\end{array}$ & $\begin{array}{l}\text { (i) DA degeneration is not progressive } \\
\text { (ii) Does not provoke Lewy body-like } \\
\text { inclusions } \\
\text { (iii) Systemic toxicity } \\
\text { (iv) Lacks external validity }\end{array}$ \\
\hline Paraquat & $\begin{array}{l}\text { (i) Potent redox cycler } \\
\text { (ii) Neuroinflammatory component }\end{array}$ & $\begin{array}{l}\text { (i) Progressive loss of DA neurons } \\
\text { (ii) Lewy-body like } \alpha \text {-synuclein } \\
\text { inclusions } \\
\text { (iii) Potential ecological validity }\end{array}$ & $\begin{array}{l}\text { (i) Inconsistent striatal DA loss and } \\
\text { motor impairment } \\
\text { (ii) Induces only moderate DA cell loss } \\
\text { when administered alone } \\
\text { (ii) Systemic toxicity }\end{array}$ \\
\hline Rotenone & $\begin{array}{l}\text { (i) Readily crosses DA neuron } \\
\text { membrane } \\
\text { (ii) Inhibits mitochondrial complex I } \\
\text { (iii) Neuroinflammatory component }\end{array}$ & $\begin{array}{l}\text { (i) Progressive loss of DA neurons } \\
\text { (ii) Lewy body-like inclusions } \\
\text { (iii) Potential ecological validity }\end{array}$ & $\begin{array}{l}\text { (i) Variable reproducibility } \\
\text { (ii) Systemic toxicity } \\
\text { (iii) Nonspecific accumulation within the } \\
\text { CNS }\end{array}$ \\
\hline LPS & Immune system activation & $\begin{array}{l}\text { (i) Progressive loss of DA neurons } \\
\text { (ii) Strong inflammatory component } \\
\text { (iii) Sensitizes DA neurons to later } \\
\text { treatment with LPS or other toxins }\end{array}$ & No Lewy body-like inclusions \\
\hline
\end{tabular}

come to influence the primary degenerative process. Thus, it is difficult to assign valence to neuroinflammatory events occurring in the PD brain on the basis of clinical autopsy studies alone. In this context, toxin-based animal models of PD provide a suitable and ecologically relevant means of assessing the role and disease-modulating capability of inflammatory responses that are either mounted or sustained by the CNS.

In addition to the infiltration of immune cells into the brain parenchyma, substantial evidence has revealed that immune factors can influence CNS functioning through activation of receptors located on peripheral organs or the BBB. These can, in turn, promote second messenger cascades or stimulate neural afferents that innervate the CNS [65]. Indeed, one of the primary mechanisms facilitating neuroimmune communication is the release of soluble glycoprotein messengers called cytokines. Although cytokines are typically produced by peripheral immune cells, evidence in recent decades has also convincingly uncovered their production from CNS glial cells [66]. In particular, immunocompotent microglia produce several cytokines and bear receptors for these immunotransmitters, which can act locally in an autocrine or paracrine manner to regulate functioning of the originating or neighboring cells, respectively [67].

The list of polypeptides that comprise the rapidly growing family of cytokine immunotransmitters include; the interferons (IFN), interleukins (IL), tumor necrosis factors (TNF), chemokines (subclass of chemoattractant cytokines), and growth and cell stimulating factors. Historically, the classification of cytokines has been based upon their molecular structure, as well as common physiological actions they possess, including the production of inflammation (i.e., swelling and irritation resulting from leukocyte infiltration) or fever (pyrogenicity) [67]. IL-1 $\beta$, TNF- $\alpha$ and IL6 , which are all released from activated macrophages, are potent proinflammatory cytokines, whereas IL-4 and IL10 , which are released from T-cells, have antiinflammatory actions.

Cytokines may gain entry to the brain through sites where the BBB is somewhat compromised (i.e., areas with fewer or less complex tight junctions), namely at circumventricular organs such as the median eminence and area postrema [65]. As well, saturable carrier-mediated transport mechanisms capable of moving IL- $1 \beta$ and TNF- $\alpha$ may allow for limited penetration of cytokines into the brain $[68,69]$. Once cytokines gain entry to the brain, they interact with receptors on cells lining the $\mathrm{BBB}$, around the meninges, as well as at vascular areas of the brain [70]. Through volume diffusion, infiltrating cytokines may ultimately penetrate deep within the brain parenchyma $[71,72]$ where they can influence, among other things, neuronal $\mathrm{Ca}^{2+}$ channels and MAP kinase and COX-2 signaling [73, 74].

Pro- and- antiinflammatory cytokine levels are markedly increased by immune and traumatic insults [75]. In this regard, endothelial cells that line the interior surface of blood vessels and the brain ventricles produce IL- $1 \beta$ and IL-6, and infection or injury augments their concentration [76]. Further, microglia, which serve as the brain's own specialized immune cells, are primary cytokine producers, and the synthesis of these cytokines was augmented by head injury, stroke and neurotoxins [77-79]. 


\section{Neuroinflammatory Mechanisms of PD: Microglia, Cytokines, and Inflammatory Enzymes}

Systemic infection may interact with environmental insults to induce exaggerated neuroinflammatory, degenerative and behavioural changes in neurological patients [80]. Indeed, exposure to pathogens or cytokines might have especially marked CNS consequences when encountered in the context of concomitant chemical toxin, traumatic head injury, or psychological stressor exposure, each of which can contribute to a breakdown of the BBB, hence favoring entry of peripheral immune pathogens into the CNS. In this regard, the bacterial endotoxin, LPS, synergistically augmented DA loss in midbrain-microglia cocultures exposed to pesticides, such as rotenone [81] and these effects may be related to enhanced NADPH oxidase-mediated release of the superoxide radical [27]. Our own work has similarly shown that a low dose of LPS enhanced the neurotoxic effects of the herbicide, paraquat, such that a substantial number of DA-producing neurons were destroyed (i.e., more than was observed with paraquat alone) and $\mathrm{PD}$-like symptoms emerged [82]. The augmented neurodegenerative response was observed when paraquat administration occurred at a time of maximal LPS-induced microglial activation (after 2 days), suggesting that the inflammatory priming sensitized microglial responding, thereby contributing to the degenerative effects of later paraquat exposure. Importantly, although relatively high concentrations of LPS alone had neurodegenerative consequences on DA neurons $[83,84]$, our studies involved relatively low concentrations of the endotoxin that alone activated microglia but had no effect upon DA neuronal survival.

The possibility exists that environmental or inflammatory toxins might promote a sensitization of neuronal processes across the lifespan, such that exposure to an immune/chemical toxin at one point in life enhances vulnerability to the behavioural and neurodestructive effects of these challenges when subsequently encountered months or even years later. In particular, at in utero and early life stages when neuronal migration and synaptic pruning are occurring, neurons are especially sensitive to perturbations caused by environmental agents. At the same time, biological detoxification systems involved in metabolism and clearance of toxic substances are not fully developed in fetuses, infants and young children. Indeed, prenatal exposure to LPS induced a relatively permanent elevation of inflammatory factors within the nigrostriatal system and reduced the number of mature DA neurons in adulthood $[85,86]$.

Exposure to LPS during critical developmental times was also found to have protracted consequences that involve a dramatic long-term sensitization of the inflammatory immune response, such that the neuroinflammatory and neurodegenerative actions of pesticides applied during adulthood were greatly enhanced $[87,88]$. As well, bacterial vaginosis, a common infection during pregnancy, has been linked to both the development of neurological disorders, including cerebral hemorrhage and cerebral palsy, and with enhanced levels of several proinflammatory cytokines, including IL- $1 \beta$,
IL-6, and TNF- $\alpha$ in adulthood $[89,90]$. Consistent with these findings, our contention has been that early immunogenic exposure may provoke mild neuroinflammation that, over time, renders neurons vulnerable to the effects of normally low-grade insults later in life. It may also be that early toxin exposure causes modest neuronal damage (or a silent lesion) that only becomes "un-masked" upon later multiple toxin exposures, again resulting in some threshold of neuronal vulnerability eventually being breached.

4.1. Role of Proinflammatory Cytokines in PD. Cytokines primarily act through either of three molecular pathways, involving activation of: (1) $\mathrm{NF} \kappa \mathrm{B}$, (2) c-Jun $\mathrm{N}$ terminal kinase (JNK), or (3) janus kinase (JAK) and signal transducer and activator of transcription (STAT). The latter two pathways involve the sequential phosphorylation of a series of intracellular proteins following administration of several cytokines, including IL-6, IL-10 and IFN- $\gamma$, resulting in the production of factors important for inflammatory and neuronal processes [91]. Similarly, the production of immune and CNS factors, including the inflammatory enzyme, COX2 , occurs following $\mathrm{NF} \kappa \mathrm{B}$ activation. In particular, IL- $1 \beta$ and TNF- $\alpha$ trigger the phosphorylation and degradation of the inhibitory factor, $\mathrm{I} \kappa \mathrm{B}$, which normally holds $\mathrm{NF} \kappa \mathrm{B}$ in an inactive state, resulting in its translocation to the nucleus where it influences (inflammatory) gene expression. In fact, we found that COX-2 deletion markedly influenced the production of cytokines following stressor and endotoxin exposure [92].

Increasingly, cytokines have been implicated in acute and chronic neuronal demise [91]. Indeed, clinical studies revealed augmented levels of proinflammatory cytokines (TNF- $\alpha$, IL-6, IL- $1 \beta$, IFN- $\gamma$ ) in postmortem brain as well as in the blood and/or cerebral spinal fluid (CSF) of patients with stroke, head injury, AD and PD [62, 93-95]. A further recent study found that $\mathrm{PD}$ patients had elevated basal and LPS-induced blood levels of numerous proinflammatory cytokines, including MCP-1, RANTES, MIP- $1 \alpha$, IL-8, IFN- $\gamma$, IL- $1 \beta$ and TNF- $\alpha$; and significant correlations were observed between cytokine levels and severity of parkinsonism [96]. Although many of these findings have been recapitulated in animal models, it is still uncertain whether these cytokines primarily play a neuroprotective or neurodestructive role. It may be that relatively low endogenous cytokine levels act in a protective capacity to buffer against damage related to death processes, whereas relatively high levels of these factors contribute to neuronal damage [97]. Indeed, low levels of cytokines can provoke the release of potentially beneficial trophic factors (BDNF, GDNF) and free radical scavengers (MnSOD), but elevated levels can activate oxidative-inflammatory cascades or even induce apoptotic death (self-destructive programmed death mechanism) [98, 99]. For instance, mice genetically lacking TNF- $\alpha$ receptors (thereby removing the influence of low endogenous levels of TNF- $\alpha$ ) were more susceptible to ischemic injury [97]; yet, administration of exogenous TNF- $\alpha$ at the time of ischemia exacerbated neuronal death [100]. Likewise, administration of the endogenous IL-1 antagonist, IL-1ra, reduced infarct size in response to middle cerebral artery occlusion and 
prevented the accumulation of inflammatory infiltrates within the area of damage [101], suggesting a prominent destructive role for IL-1 in acute cerebrovascular insults. In effect, the concentration as well as timing of cytokine exposure likely determines whether primarily protective or deleterious consequences arise from these immunotransmitters.

4.1.1. Interferons in PD. Interferons (IFNs) are broadly divided into either type I IFNs, including the IFN- $\alpha$ and IFN$\beta$ isoforms, which originated from a common ancestral gene, or the structurally unrelated type II form, IFN- $\gamma$ (formerly called macrophage activating factor). The main signaling pathways utilized by the IFNs involve the sequential phosphorylation of STATs by intracellular JAK protein kinases (stimulated by ligand-receptor binding). IFN- $\gamma$ is secreted predominantly from type 1 helper T lymphocytes (Th1) and natural killer (NK) cells; yet, recent reports indicate that the cytokine is also synthesized de novo within the brain by activated microglia [102]. In contrast, the production of IFN- $\alpha$ and IFN- $\beta$ does not appear to be under the control of specific cell types, and indeed, most cells appear to be able to secrete these cytokines in response to viral insult [103]. Although IFNs were originally believed to be exclusively antiviral substances, it has become apparent that the cytokine family is involved in a broad array of immunoregulatory functions that may either inhibit or promote disease states within the periphery or CNS (e.g., cancer, chronic microbial or parasitic infection) $[104,105]$.

Cancer and hepatitis $\mathrm{C}$ patients receiving IFN- $\alpha$ immunotherapy have been observed in many instances to develop a PD-like syndrome, including tremors, muscle rigidity and a generalized paucity of movement [106, 107]; and postmortem examination of $\mathrm{PD}$ brains revealed the presence of MxA (type I IFN-inducible GTPase) in SNc Lewy bodies and neuronal swellings [108, 109]. Similarly, recent data suggest an important role for IFN- $\gamma$ in MPTP and paraquat animal models of $\mathrm{PD}[42,110]$. In corroboration of these results, IFN- $\gamma$ levels are elevated in the blood [110, 111] and postmortem SNc brain tissue $[112,113]$ of PD patients; and a polymorphism in the gene coding for IFN- $\gamma$ differentially modified the risk of developing early- or late-onset PD [114]. In addition, levels of serum and CSF neopterin, a pteridine marker of IFN$\gamma$-associated immune system activation, are elevated in $\mathrm{PD}$ patients and tend to be highest among those with more severe symptoms [115]. Indeed, PD patients exhibit fewer infectious episodes and malignancies [116, 117], possibly stemming from enhanced proinflammatory IFN signaling.

Interestingly, a recent study [118] indicated that IFN- $\gamma$ is capable of inflicting direct excitotoxic neuronal damage by signaling through a distinct, neuron-specific receptor complex formed by the IFN- $\gamma$ receptor and the AMPA receptor GluR1 subunit. In this way, IFN- $\gamma$ was observed to induce dendritic beading in mouse cortical neurons secondary to an increase in $\mathrm{Ca}^{2+}$ influx, nitric oxide (NO) generation and ATP depletion [118]. However, most available evidence suggests that IFN- $\gamma$ likely influences neuronal survival and functioning through its actions on glial cells, particularly microglia.

While the microglial gene network subject to regulatory control by IFN- $\gamma$ is both extensive and diverse (reflecting the pleiotropic nature of IFN- $\gamma$ and cytokines in general), a number of positively regulated IFN- $\gamma$-responsive genes (i.e., those containing GAS (gamma activation sequence), IRF-E (interferon regulatory factor element), or ISRE (interferonstimulated response element) binding sites) encode proteins implicated in immunoinflammatory processes $[119,120]$; and hence, may be of particular relevance for neurological disorders such as PD. For instance, IFN- $\gamma$-associated microglial JAK/STAT signaling arbitrates (either directly or indirectly via secondary transcription factors such as IRF-1) the upregulated or de novo expression of several genes encoding proteins critical for antigen presentation to lymphocytes (e.g., MHC class I/II, immunoproteasome subunits LMP-2 and LMP-7), recruitment and activation of $\mathrm{T}$ cells (i.e., chemokines and adhesion molecules), and classical pathway-dependent complement deposition [119, 120]. Importantly, many of these same immunologically relevant factors have been localized to microglia in the $\mathrm{SNc}$ of postmortem PD brains or animals exposed to DAtargeting neurotoxins $[114,121-123]$, suggesting that IFN$\gamma$ may be a critical determinant of prospective adaptive immune responses in PD.

While the pathogenic relevance of adaptive immune activation in PD has long been debated, a recent study demonstrated that mice genetically lacking mature CD4+ T lymphoctyes (but not CD8+ T cells) were protected against MPTP-induced neurodegeneration [124]. However, in this study, CD4+ T cell-mediated DA neuronal loss was found to be dependent on the presence of the TNF ligand family member, FasL, and not IFN- $\gamma$. Of course, these results do not necessarily preclude a role of IFN- $\gamma$ in $\mathrm{T}$ cellmediated dopaminergic neurodegeneration; indeed, FasL is capable of augmenting inflammatory cytokine cascades from microglia (in addition to directly mediating neuronal apoptosis), and Fas receptor expression is potently upregulated in activated microglia following inflammatory insult [125].

In addition to facilitating communication between microglia and peripheral immune cells, IFN- $\gamma$ plays a key role in the activation of oxidative and inflammatory microglial enzyme systems that evolved to protect the host against pathogenic (and possibly xenobiotic) threats to the CNS. Indeed, IFN $-\gamma$ in combination with TNF- $\alpha$ induces microglial expression of iNOS and several key subunits of NADPH oxidase [126], as well as the IFN-inducible doublestranded RNA-activated kinase, PKR [127]. Of course, NADPH oxidase and iNOS are important mediators of oxidative-nitrosative stress, and PKR, through its actions on $\mathrm{NF} \kappa \mathrm{B}$, is capable of inducing the PG- and- ROS-producing enzyme, COX-2 [128]. In fact, pretreatment with the indole hormone, melatonin, attenuated IFN- $\gamma$ - and- LPSmediated expression of COX-2 (and iNOS), and this effect was attributed to the inhibition of $\mathrm{NF} \kappa \mathrm{B}$ activation [129]. Moreover, we recently found that IFN- $\gamma$ was critical for the induction of oxidative (iNOS, NADPH oxidase subunits) and 
inflammatory $(\mathrm{COX}-2, \mathrm{NF} \kappa \mathrm{B})$ factors following paraquat treatment in a mouse model of PD [44]. Importantly, many of these factors were localized to microglia and their downregulation in the absence of IFN- $\gamma$ was associated with marked neuroprotection against paraquat [44]. Accordingly, IFN- $\gamma$ may impact neuronal survival by way of its downstream effects on key microglial enzymes implicated in the elaboration of deleterious inflammatory factors (i.e., NO, ROS, prostanoids).

Likewise, the proinflammatory interleukins, IL-7, IL15 , IL-12, IL1- $\alpha$, and IL-1 $\beta$, are subject to upregulation by IFN- $\gamma$ at the gene level in microglia (either directly or indirectly; e.g., IFN- $\gamma$ upregulates caspase- 1 , which in turn activates IL-1 $\beta)[120,130]$, suggesting that type II IFN may be an early mover of proinflammatory cytokine cascades. Further, some of these cytokines (including IFN$\gamma$ itself) can skew CD4+ T cell development towards a Th1/proinflammatory phenotype, which has, in fact, been described in PD [131]. In addition, IFN- $\gamma$ stimulates TNF$\alpha$ production in microglia, presumably through the sensitization of these cells to antigens (e.g., LPS) and, potentially, xenobiotic agents (e.g., pesticides) [132]. Importantly, our laboratory observed that the loss of DA neurons induced by paraquat treatment was associated with enhanced IL- $1 \beta$ and TNF- $\alpha$ mRNA within the SNc [44]. Moreover, IFN$\gamma$-deficient mice failed to show such cytokine elevations and DA neuronal degeneration in response to the pesticide [44], indicating once again that IFN- $\gamma$ might be a pivotal mediator of toxin-induced inflammatory and degenerative pathology.

IFN- $\gamma$ signaling may also drive the downregulation of several ostensibly neuroprotective species in microglial cells, which could increase neuronal vulnerability to oxidative and inflammatory damage. For instance, IFN- $\gamma$ dampened microglial expression of the antiinflammatory cytokine, IL-10 [120], as well as the soluble trophic factor, insulinlike growth factor (IGF)-1 [119], both of which have been shown to exert neuroprotective effects in toxin-based animal models of PD [133-135]. Similarly, Moran and colleagues [130] reported that the expression levels of osteopontin, a secretory phosphoprotein with antiapoptotic properties that can attenuate the neurodegenerative consequences of stroke [136] and MPTP (at least in common marmosets) [137], were suppressed in IFN- $\gamma$-activated microglia [130]. It ought to be mentioned that genetic ablation of osteopontin actually mitigated the SNc neuronal loss and striatal DA denervation following MPTP intoxication in mice, suggesting that osteopontin may, in fact, contribute to DA neurodegeneration [138]. Yet, IFN- $\gamma$ activity was not directly assessed in this study (although the MPTP-treated wildtype mice displayed osteopontin-positive reactive microglia [138]), and interspecies variability in MPTP sensitivity could conceivably account for the discrepancy between the studies. In essence, IFN- $\gamma$ may contribute to the neurodegenerative response in PD and its toxin-based animal models by mediating not only the activation of critical immune effector mechanisms, but also the suppression of microglial processes more closely aligned with antiinflammation and immune resolution.
In addition to microglia, recent evidence suggests that astrocytes may mediate some of the central immunomodulatory actions of IFN- $\gamma$, potentially through STAT1independent signal transduction pathways. For instance, Hashioka and colleagues [139] found that IFN- $\gamma$ (but not LPS, TNF- $\alpha$, or IL- $1 \beta$ ) caused astroctyes to become neurotoxic in vitro, reducing the viability of cultured neuroblastoma cells. Moreover, inhibition of STAT3 reduced the neurotoxic potential of these IFN- $\gamma$-activated astrocytic cells [140]. In contrast, several other reports indicated that IFN- $\gamma$ signaling in astrocytes mediates primarily neuroprotective events. Indeed, IFN- $\gamma$-induced activation of astrocytes attenuated hippocampal neuronal damage after status epilepticus (SE) in rats, while neutralization of astrocytic IFN- $\gamma$ receptors aggravated SE-induced neuronal pathology [141]. Likewise, combined IFN- $\gamma$ and LPS treatment reduced apoptosis of hippocampal neurons induced by in vitro application of beta-amyloid protein, but only in the presence of astrocytes [142]. In fact, Ramírez et al. [142] provided evidence linking this antiapoptotic effect to the upregulated secretion of the antiinflammatory cytokine, transforming growth factor (TGF)- $\beta$, from IFN- $\gamma$ - and LPS-activated astrocytes. Thus, while there is much still to be elucidated regarding the complex nature of brain IFN signaling in health and disease (e.g., cellular targets, effector molecules), a large body of evidence suggests a potentially central role for this cytokine group, particularly IFN- $\gamma$, in mediating aspects of the inflammatory repertoire and neurodegenerative process of PD.

\subsubsection{Interleukins and Tumor Necrosis Factor- $\alpha$ in PD.} The cysteine protease, interleukin-converting enzyme (caspase-1), cleaves the $31-33 \mathrm{kDa}$ precursor, proIL-1, to form the mature and biologically active IL- $1 \alpha$ and IL- $1 \beta$ cytokines [143]. Some of the synthesized IL-1 is secreted in a soluble form, but a proportion is retained within the cell membrane [144]. Both the soluble and membrane-bound forms of IL-1 are biologically active, particularly with respect to lymphocyte activation [144]. IL-1 signaling is dependent upon its type I receptor and the IL-1 receptor accessory protein, which are located on adjacent portions of the membrane [145]. Much like IL- $1 \beta$, TNF- $\alpha$ is a pleiotropic cytokine, which exerts a wide array of actions on numerous cell types. For instance, it has physiological actions on bone osteoclasts (important for rheumatoid arthritis), mononuclear and polymorphonuclear blood cells, fibroblasts, skin keratinocytes, insulin sensitive adipocytes, as well as brain neurons and glial cells [146]. Like other cytokines, TNF- $\alpha$ typically acts locally at the site of generation; however, small amounts of the cytokine are found circulating in the bloodstream.

As in the case of IFN- $\gamma$, mounting evidence suggests a role for ILs and TNF- $\alpha$ in PD. Specifically, postmortem analyses of PD brain tissue revealed increased expression of TNF- $\alpha$ and its related Fas receptor, as well as the cytokines IFN- $\gamma$, IL-1 $\beta$ and IL-6 [15]. Likewise, in animals, MPTP induced alterations of proinflammatory cytokine genes, including those encoding IL- $1 \beta$ and TNF- $\alpha$ [147, 148]; and the DA neurotoxin, 6-OHDA, increased levels 
of these cytokines within the SNc and striatum [149]. Indeed, an increasing number of studies are beginning to assess the impact of cytokine manipulations on PDlike pathology. In this regard, both systemic and central administration of IL- $1 \beta$ was reported to affect SNc DA neuronal survival. Indeed, pharmacological inhibition of IL- $1 \beta$ attenuated the loss of DA neurons provoked by intra-SNc infusion of LPS together with 6-OHDA injection [150]. Moreover, direct application of IL- $1 \beta$ augmented the neurodestructive effects of 6-OHDA upon cultured midbrain neurons [151]. Somewhat surprisingly, chronic adenoviral induced expression of IL-1 $\beta$ in the striatum also induced a loss of SNc DA neurons [152], suggesting that the cytokine can exert damaging effects upon DA terminals that result in the retrograde destruction of upstream soma. Importantly, the IL-1 $\beta$ induced loss of neurons was associated with motor impairment and an enhanced microglial response; and antiinflammatory treatment prevented these effects [152]. Yet, other older studies reported that central infusion of IL$1 \beta$ protected DA neurons from 6-OHDA and MPTP toxicity and induced dendritic branching from residual neurons following SNc lesion [153, 154]. The discrepancies between the studies remain to be explained but likely stem from dose and timing considerations, since, as already mentioned, some cytokines might have both protective and deleterious effects depending on their concentration and the state of the microenvironment in which they act.

Involvement of TNF- $\alpha$ in PD, like IL- $1 \beta$, is somewhat controversial, with two conflicting reports indicating that TNF- $\alpha$ deletion either protected striatal terminals and normalized DA levels in MPTP-treated mice $[155,156]$ or increased DA metabolism, without necessarily affecting neuronal survival [157]. Interestingly, in one study there was no effect of intra-SNc infusion of TNF- $\alpha$ or IL- $1 \beta$ either alone or together upon neuronal survival [84], but the source for this outcome is uncertain. More recently, adenoviral vector mediated long-term expression of TNF$\alpha$ within the SNc was reported to provoke a progressive loss of DA neurons over 28 days that was associated with irreversible akinesia [158]. Likewise, overexpression of a dominant negative TNF- $\alpha$ protein (inhibits endogenous TNF- $\alpha$ ) in the SNc ameliorated the loss of DA neurons and motor impairment induced by 6-OHDA treatment [159].

The cytokines IL- $1 \beta$ and TNF- $\alpha$ typically influence central processes through $\mathrm{NF} \kappa \mathrm{B}$, a transcription factor that plays a critical role in the regulation of innate and adaptive immune reactions, including the mobilization of inflammatory chemokines and lymphocyte proliferative responses following infection or traumatic injury $[160,161]$. Indeed, $\mathrm{NF} \kappa \mathrm{B}$ signaling occurs ubiquitously throughout the brain, and IL- $1 \beta$ infusion into the lateral ventricles induced the translocation of $\mathrm{NF} \kappa \mathrm{B}$ to the nucleus at several brain regions distal to the site of infusion, including the choroid plexus, ependymal cells, cerebral vasculature and meninges [162].

$\mathrm{NF} \kappa \mathrm{B}$ is composed of five subunits, together with a nuclear localization signal, which are normally held in an inactive state by an endogenous inhibitory factor, $\mathrm{I} \kappa \mathrm{B}$. However, exposure to inflammatory stimuli triggers the phosphorylation and consequent degradation of $I \kappa \mathrm{B}$, resulting in the translocation of $\mathrm{NF} \kappa \mathrm{B}$ to the nucleus where it promotes gene expression [160]. Immunological insults may initiate this $\mathrm{NF} \kappa \mathrm{B}$ cascade through the provocation of cytokines, particularly IL- $1 \beta$ and TNF- $\alpha$, which, after binding to their cell surface receptors, stimulate kinases that target $\mathrm{I} \kappa \mathrm{B}$ for ubiquitination and subsequent proteasomal degradation [160]. As well, these cytokines may also affect CNS processes by stimulating NF $\kappa B$ signaling cascades.

$\mathrm{NF} \kappa \mathrm{B}$ appears to have potent effects upon CNS processes important for neuronal survival and plasticity. The transcription factor may have a neuroprotective role through the induction of antiapoptotic proteins, such as Bcl-2 and the antioxidant enzyme, manganese superoxide dismutase (MnSOD) [163]. Yet, $\mathrm{NF} \kappa \mathrm{B}$ signaling may also result in the synthesis or upregulation of inflammatory cytokines and enzymes, ROS, and excitotoxins that can contribute to neurodegeneration. For instance, iNOS expression within microglia and astrocytes is readily provoked by $\mathrm{NF} \kappa \mathrm{B}$ activation following exposure to cytokines, such as IL$1 \beta$ or IL-12 $[164,165]$. Similarly, stressor exposure may contribute to neurological pathology by affecting $\mathrm{NF} \kappa \mathrm{B}-$ mediated production of oxidative radicals given that restraint stress was shown to promote neuronal excitotoxicity in rats that was associated with enhanced TNF- $\alpha$ release and $\mathrm{NF} \kappa \mathrm{B}$ mediated activation of iNOS and COX-2 [166]. Ultimately, a host of factors, including the chronicity and type of inducing stimulus, likely influence whether $\mathrm{NF} \kappa \mathrm{B}$ activation has protective or detrimental effects upon neuronal survival or functioning.

4.2. Cyclooxygenase-2 in PD. Cyclooxygenase, present in the CNS as COX-1, COX-2 and COX-3 isoforms, is an integral plasma membrane glycoprotein critically involved in the production of PGs from arachidonic acid (AA). The first step in PG biosynthesis involves the conversion of glycerophospholipid into free AA by phospholipase A2, which is ubiquitously present in all brain tissues and whose expression is upregulated by infection or injury [167]. Thereafter, COX metabolizes AA into PGG2 and then PGH2, which is transformed further by terminal synthases into specific PG species. AA is preferentially metabolized by COX-2 to PGE2 (the most abundant PG), whereas COX-1 produces only small amounts of this prostanoid [168]. In addition to these biologically active lipid mediators, substantial amounts of ROS are formed during the COX-mediated peroxidative reduction of PGG2 to PGH2.

Within the CNS, all three COX isozymes are expressed and heterogeneously distributed in several discrete neural populations where they mediate a diverse range of functions in health and disease. COX-1 may be generally described as a constitutive "housekeeping" enzyme, supplying PGs at (low) levels relevant for the regulation of myriad homeostatic brain processes (e.g., cerebral blood flow) [167]. Much less is known regarding the functions of COX-3 (which appears to be splice variant of COX-1); however, preliminary evidence suggests that the recently discovered COX isozyme may be important for species-specific febrile responses and the processing of painful stimuli $[169,170]$. Contrastingly, under normal physiological conditions COX-2 partakes 
in a diverse array of response-related activities, including synaptic plasticity and signaling, neurotransmission, memory consolidation during rapid eye movement (REM) sleep, membrane excitability, and gene expression [167, 171]. Indeed, the COX-2 gene promoter contains multiple regulatory elements (e.g., that recognize glucocorticoids, cytokines, $\mathrm{NF} \kappa \mathrm{B}, \mathrm{cAMP}$, and $\mathrm{CREB}$ ) that either enhance or suppress COX-2 transcription [171, 172].

Not surprisingly, COX-2 is subject to induction by a variety of inflammatory stimuli, many of which (e.g., cytokines, ROS) have been implicated in the generalized activation of microglial cells in response to and as a corollary of acute inflammation associated with infection, brain injury or neurodegeneration. For instance, administration of the bacterial endotoxin, LPS, or the DA toxin, MPTP, elicited a marked increase in microglial COX-2 expression [173, 174]. Yet, COX-2 is also present in neurons, and is similarly induced during inflammatory episodes [17].

As is the case for proinflammatory cytokines, substantial evidence indicates that COX-2 may play an important role in the neurodegenerative process of $\mathrm{PD}$ and its animal models. In this regard, COX-2 expression was elevated in microglial cells [175] and DA neurons [176] within the SNc of postmortem PD brain (although the latter study failed to detect increased COX-2 in microglia). Likewise, MPTPintoxicated mice displayed augmented COX-2 immunoreactivity within both SNc neurons [176] and microglia [174], and pharmacologic inhibition or genetic ablation of COX2 prevented the loss of DA neurons following exposure to MPTP or 6-OHDA $[177,178]$. Similarly, Yang and colleagues [179] recently demonstrated the crucial role of COX-2 in paraquat-induced neurotoxicity in vitro, and our group found that mice genetically lacking COX-2 were resistant to the PD-like neurological (nigrostriatal DA transmission) and behavioural (bradykinesia) effects of the pesticide [180].

Interestingly, several epidemiological reports indicated that NSAIDs, which act primarily to inhibit COX-2 (but also scavenge ROS and RNS [181, 182]), might either prevent or delay PD onset [183-185]. Yet, numerous other contemporaneous studies have failed to find compelling evidence of a protective role of such drugs in PD [186188]. Although consensus remains elusive, a recent metaanalysis evaluating the impact of NSAIDs on PD risk revealed that regular, long-term use of nonaspirin NSAIDs (but not aspirin or acetamenophen) reduced PD incidence by roughly $15 \%$ [189].

Inflammatory PG signaling, which is mediated in large part by PGE2, constitutes a primary mechanism by which COX-2 might come to influence neuronal functioning and survival in neurological illness. For instance, PGE2 signaling through the EP1 receptor provoked cAMP-dependent apoptosis of hippocampal neurons [190], and pharmacological blockade of EP1 receptors completely prevented DA neuron loss following 6-OHDA treatment in embryonic rat mesencephalic primary neuronal cultures [191]. Emerging evidence indicates that PGE2 may act in an autocrine or paracrine manner to augment the COX-2-dependent microglial (and possibly neuronal) production of further prostanoid species [192, 193]. Indeed, PGE2 is capable of promoting the inherent transcriptional activities of $\mathrm{NF} \kappa \mathrm{B}$ [194], which can then exert trans-activational control over the COX-2 gene promoter [195]. In this way, PG signaling between neural cells might serve in the recruitment of otherwise quiescent microglia and augment the synthesis and release of inflammatory mediators, including further PG species, from heretofore activated microglial cells $[174,196]$. This, in turn, would of course be expected to exacerbate ongoing DA neurodegeneration.

It ought to be underscored, however, that despite the evidence seemingly linking microglial COX-2 to DA neuronal death, there remains considerable controversy surrounding the relative contribution (and functional relevance) of microglial versus neuronal COX-2 in PD. Indeed, several reports indicated that a JNK-mediated induction of COX-2 in neurons but not microglia is critical for DA neuron cytotoxicity following MPTP treatment [197, 198]. Moreover, Teismann and colleagues [176] provided compelling evidence favoring the importance of cell-autonomous oxidative processes (i.e., COX-2-derived ROS, DA-quinone formation) over PG-mediated inflammatory ones in COX-2dependent neurodegeneration. Similarly, increased neuronal COX-2 activity has been implicated in paraquat-induced neurotoxicity [179]; and, while the regulatory mechanisms subserving neuronal COX-2 induction by paraquat have yet to be defined, there is reason to believe that JNK pathway activation may be critical, given the importance of JNK in mediating the ROS-dependent in vitro and in vivo neurodegenerative effects of paraquat upon DA neurons $[199,200]$. In contrast, the findings of a recent study in monkeys suggested that neuronal COX-2 expression was not associated with increased susceptibility to MPTPinduced neurodegeneration [201]; and Boyd et al. [202] observed robust strain-specific differences in neuronal COX2 responses to MPTP in mice. In short, while the cellular and molecular determinants of brain COX-2 expression in neurological illness remain somewhat controversial, it is relatively certain that inflammatory and/or oxidative responses mediated by inducible COX-2 activity contribute to the neurodegenerative process of $\mathrm{PD}$ and its animal models.

It is also worth noting that COX-2, in addition to mediating potentially deleterious proinflammatory and prooxidative responses, appears to promote inflammatory immune resolution both in the CNS and the periphery. Consistent with this notion, even as PGE2 signaling through EP1 receptors is implicated in COX-2-mediated neurotoxic events, EP2/EP4 receptor signaling often mediates prosurvival responses. For instance, stimulation of EP2 and/or EP4 receptors prevented neuronal death following excitotoxic/ischemic insult $[203,204]$ and antagonized the neurotoxic effects of beta-amyloid [205], 6-OHDA [206] and LPS [207]. More generally, multiple COX-2-derived prostanoids seem able to promote central immunosuppressive/antiinflammatory responses by directing a reduction in proinflammatory factors (e.g., TNF- $\alpha, \mathrm{NO}$ ) or an increase in antiinflammatory ones (e.g., IL-10, BDNF) [208, 209]. Further, other nonprostanoid COX (and lipoxygenase) derived lipid mediators, particularly the recently discovered 


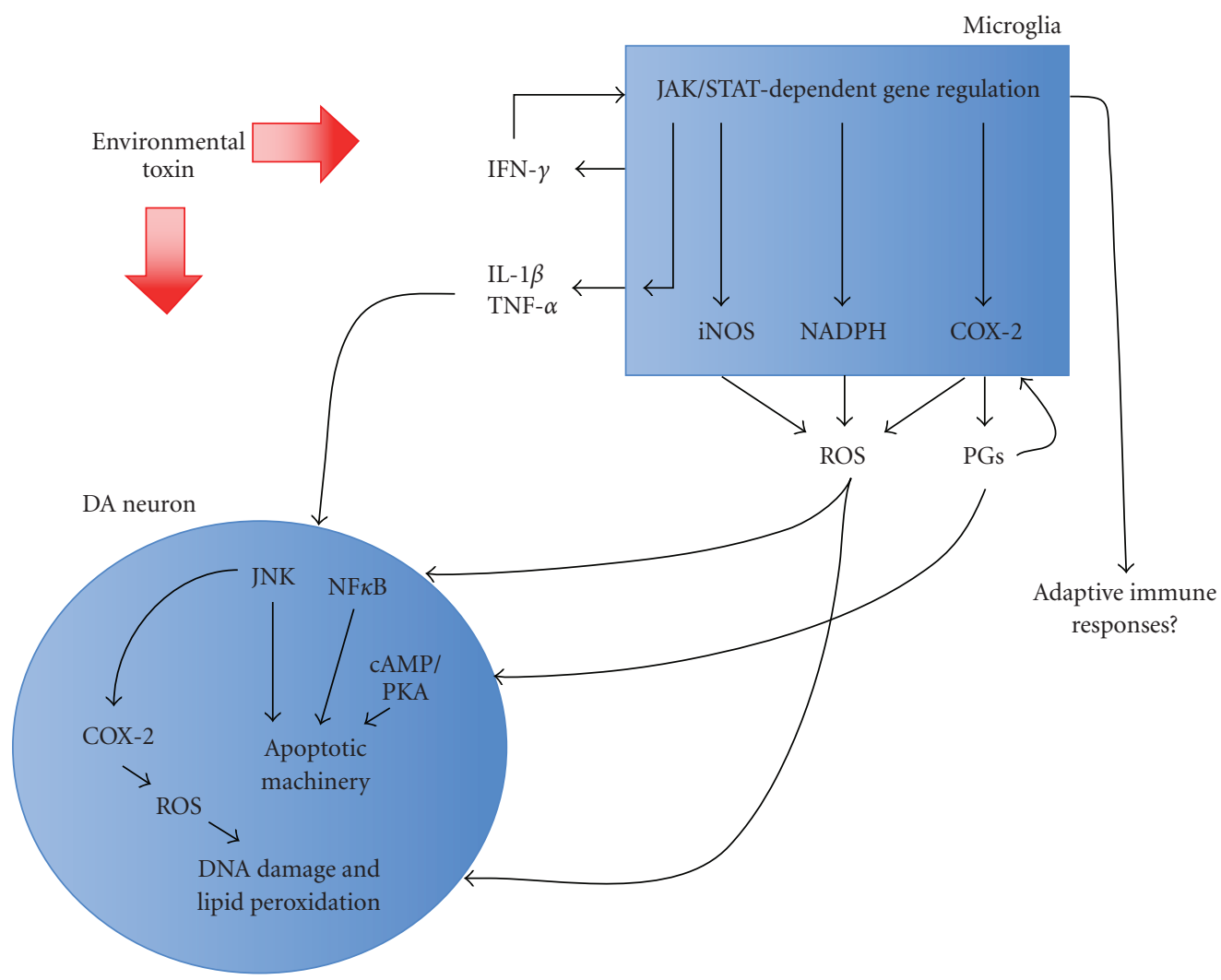

Figure 1: Conceptual overview of how environmental toxins may provoke DA neurodegeneration in Parkinson's disease and its animal models. Chronically activated microglia are integral mediators of pathology, synthesizing and secreting a plethora of prooxidant and proinflammatory factors, several of which (e.g., IFN- $\gamma$, PGs) may form positive feedback loops to stimulate the production of further inflammatory/oxidative factors (e.g., ROS, PGs) by microglial cells. Several mutually nonexclusive mechanisms exist whereby toxin-induced microglial release of prooxidant/inflammatory agents may lead to DA neurodegeneration; these include lipid peroxidation, DNA damage and the activation of intracellular apoptotic pathways. Additionally, there is evidence to suggest that both adaptive immune responses (e.g., T cell-dependent) and cell-autonomous oxidative processes (e.g., DA-quinone formation) may contribute to DA neuronal loss in PD.

DHA-derived docosanoids (resolvins and neuroprotectins), appear to antagonize the inflammatory actions of COX-2 and curb proinflammatory CNS responses more generally (e.g., inhibit $\mathrm{NF} \kappa \mathrm{B}$, up/downregulate anti/proapoptotic proteins, suppress cytokine synthesis, modulate leukocyte trafficking) $[210,211]$. It is conceivable that variations in COX-2 signaling that favor EP2/EP4 receptor involvement, and hence DA neuronal survival, might occur in conjunction with certain cytokine profiles and inflammatory responses following DA neuron injury. It might even be the case that the nature of the inflammatory response (involving COX-2 and cytokines) might vary over time following insult, such that there may be a waxing and waning of neuroprotective versus neurotoxic mechanisms engaged.

\section{Conclusions and Future Directions}

The findings discussed in this paper provide support for a role of proinflammatory factors, particularly cytokines (IFN- $\gamma$, IL- $1 \beta$, TNF- $\alpha$ ) and inducible enzymes (COX-2), as well as their associated inflammatory signaling pathways (e.g., JAK-STAT, NF $\kappa \mathrm{B}$, and MAP kinases), in the prodeath processes operating in PD (see Figure 1); and hence, support the contention that antiinflammatory treatments might have general clinical utility for PD and other neurodegenerative conditions. Given the complexities of the inflammatory response, future efforts would be wise to focus on developing more selective immune modulatory agents that target specific cytokines (and other inflammatory mediators) at certain stages of PD. This is not to say that such antiinflammatory agents should replace conventional treatments, rather these novel drugs might be useful as adjuncts or "add-ons" to existing therapies. Indeed, owing to the multifaceted nature of and likely multiple mechanisms involved in neurological illnesses such as PD, a multipronged drug approach seems reasonable.

While it seems undeniable that the inflammatory immune response plays a crucial role in dopaminergic loss and the clinical symptoms observed in PD, it remains to be determined whether neuroinflammation is most relevant to disease process genesis or, rather, is secondarily induced following neuronal injury and thus more critically aligned with shaping the evolution of pathology over time. The emerging picture does suggest, however, that one important mechanism underlying DA neuronal loss in toxin-based animal models of PD involves the (chronic) activation 
of microglial cells, which through the actions of proinflammatory cytokines and inducible enzymes, mediates the production of damaging oxidative radicals and soluble inflammatory mediators.

While excessive microglial and proinflammatory cytokine driven inflammation can mediate profoundly deleterious CNS consequences, including DA neurodegeneration in PD and its toxin-based animal models, it should be underscored that many aspects of immune surveillance and glial activity are essential for brain health. Indeed, routine trafficking of $\mathrm{T}$ lymphocytes into the CSF and microglia-neuron and microglia-astrocyte interactions are critical for protecting the CNS from invading pathogens, regulating extracellular fluid composition, removing potentially harmful cellular debris, and promoting adaptive neuroplastic responses to CNS challenge. Hence, a delicate balance exists between the positive and negative aspects of immune-inflammatory signaling in the CNS. Problems likely arise when environmental toxins or other external challenges overwhelm and usurp the natural plasticity of neuroinflammatory responses to promote an abnormal, hyperactive microglial state that encourages overzealous oxidative/inflammatory factor release.

\section{Acknowledgments}

D. Litteljohn and S. Hayley were supported by funds from the Canadian Institutes of Health Research (CIHR) and Parkinson's Society Canada. S. Hayley holds a Canada Research Chair in Behavioural Neuroscience.

\section{References}

[1] T. Klockgether, "Parkinson's disease: clinical aspects," Cell and Tissue Research, vol. 318, no. 1, pp. 115-120, 2004.

[2] M. Menza, R. D. Dobkin, and H. Marin, "Treatment of depression in parkinson's disease," Current Psychiatry Reports, vol. 8, no. 3, pp. 234-240, 2006.

[3] R. M. Marié, L. Barré, B. Dupuy, F. Viader, G. Defer, and J. C. Baron, "Relationships between striatal dopamine denervation and frontal executive tests in Parkinson's disease," Neuroscience Letters, vol. 260, no. 2, pp. 77-80, 1999.

[4] E. C. Wolters and H. Braak, "Parkinson's disease: premotor clinico-pathological correlations," Journal of Neural Transmission, Supplement, no. 70, pp. 309-319, 2006.

[5] V. S. Kostić, F. Agosta, I. Petrović et al., "Regional patterns of brain tissue loss associated with depression in Parkinson disease," Neurology, vol. 75, no. 10, pp. 857-863, 2010.

[6] F. D. Dick, G. de Palma, A. Ahmadi et al., "Environmental risk factors for Parkinson's disease and parkinsonism: the Geoparkinson study," Occupational and Environmental Medicine, vol. 64, no. 10, pp. 666-672, 2007.

[7] M. G. Weisskopf, J. Weuve, H. Nie et al., "Association of cumulative lead exposure with Parkinson's disease," Environmental Health Perspectives, vol. 118, no. 11, pp. 1609-1613, 2010.

[8] A. L. McCormack, M. Thiruchelvam, A. B. Manning-Bog et al., "Environmental risk factors and Parkinson's disease: selective degeneration of nigral dopaminergic neurons caused by the herbicide paraquat," Neurobiology of Disease, vol. 10, no. 2, pp. 119-127, 2002.

[9] J. R. Cannon, V. Tapias, H. M. Na, A. S. Honick, R. E. Drolet, and J. T. Greenamyre, "A highly reproducible rotenone model of Parkinson's disease," Neurobiology of Disease, vol. 34, no. 2, pp. 279-290, 2009.

[10] L. M. Bolin, I. Strycharska-Orczyk, R. Murray, J. W. Langston, and D. Di Monte, "Increased vulnerability of dopaminergic neurons in MPTP-lesioned interleukin-6 deficient mice," Journal of Neurochemistry, vol. 83, no. 1, pp. 167175, 2002.

[11] K. Sriram, J. M. Matheson, S. A. Benkovic, D. B. Miller, M. I. Luster, and J. P. O'Callaghan, "Deficiency of TNF receptors suppresses microglial activation and alters the susceptibility of brain regions to MPTP-induced neurotoxicity: role of TNF- $\alpha$," FASEB Journal, vol. 20, no. 6, pp. 670-682, 2006.

[12] M. G. Purisai, A. L. McCormack, S. Cumine, J. Li, M. Z. Isla, and D. A. Di Monte, "Microglial activation as a priming event leading to paraquat-induced dopaminergic cell degeneration," Neurobiology of Disease, vol. 25, no. 2, pp. 392-400, 2007.

[13] V. Sanchez-Guajardo, F. Febbraro, D. Kirik, and M. Romero-Ramos, "Microglia acquire distinct activation profiles depending on the degree of $\alpha$-synuclein neuropathology in a rAAV based model of Parkinson's disease," PLOS ONE, vol. 5, no. 1, article e8784, 2010.

[14] P. L. McGeer, S. Itagaki, B. E. Boyes, and E. G. McGeer, "Reactive microglia are positive for HLA-DR in the substantia nigra of Parkinson's and Alzheimer's disease brains," Neurology, vol. 38, no. 8, pp. 1285-1291, 1988.

[15] T. Nagatsu, M. Mogi, H. Ichinose, and A. Togari, "Changes in cytokines and neurotrophins in Parkinson's disease," Journal of Neural Transmission, Supplement, no. 60, pp. 277-290, 2000.

[16] S. Hunot, F. Boissière, B. Faucheux et al., "Nitric oxide synthase and neuronal vulnerability in Parkinson's disease," Neuroscience, vol. 72, no. 2, pp. 355-363, 1996.

[17] E. C. Hirsch and S. Hunot, "Neuroinflammation in Parkinson's disease: a target for neuroprotection?" Lancet Neurology, vol. 8, no. 4, pp. 382-397, 2009.

[18] D. Davalos, J. Grutzendler, G. Yang et al., "ATP mediates rapid microglial response to local brain injury in vivo," Nature Neuroscience, vol. 8, no. 6, pp. 752-758, 2005.

[19] A. Nimmerjahn, F. Kirchhoff, and F. Helmchen, "Neuroscience: resting microglial cells are highly dynamic surveillants of brain parenchyma in vivo," Science, vol. 308, no. 5726, pp. 1314-1318, 2005.

[20] M. L. Cotrina, J. H. C. Lin, J. C. López-García, C. C. G. Naus, and M. Nedergaard, "ATP-mediated glia signaling," Journal of Neuroscience, vol. 20, no. 8, pp. 2835-2844, 2000.

[21] P. G. Popovich and E. E. Longbrake, "Can the immune system be harnessed to repair the CNS?" Nature Reviews Neuroscience, vol. 9, no. 6, pp. 481-493, 2008.

[22] A. Michelucci, T. Heurtaux, L. Grandbarbe, E. Morga, and P. Heuschling, "Characterization of the microglial phenotype under specific pro-inflammatory and anti-inflammatory conditions: effects of oligomeric and fibrillar amyloid- $\beta$," Journal of Neuroimmunology, vol. 210, no. 1-2, pp. 3-12, 2009.

[23] Z. C. Baquet, P. C. Bickford, and K. R. Jones, "Brain-derived neurotrophic factor is required for the establishment of the proper number of dopaminergic neurons in the substantia nigra pars compacta," Journal of Neuroscience, vol. 25, no. 26, pp. 6251-6259, 2005.

[24] A. L. Peterson and J. G. Nutt, “Treatment of Parkinson's disease with trophic factors," Neurotherapeutics, vol. 5, no. 2, pp. 270-280, 2008. 
[25] H. M. Gao and J. S. Hong, "Why neurodegenerative diseases are progressive: uncontrolled inflammation drives disease progression," Trends in Immunology, vol. 29, no. 8, pp. 357365, 2008.

[26] J. Anrather, G. Racchumi, and C. Iadecola, "NF- $\kappa$ B regulates phagocytic NADPH oxidase by inducing the expression of gp91phox," Journal of Biological Chemistry, vol. 281, no. 9, pp. 5657-5667, 2006.

[27] H. M. Gao, B. Liu, W. Zhang, and J. S. Hong, "Critical role of microglial NADPH oxidase-derived free radicals in the in vitro MPTP model of Parkinson's disease," FASEB Journal, vol. 17, no. 13, pp. 1954-1956, 2003.

[28] D. C. Wu, P. Teismann, K. Tieu et al., "NADPH oxidase mediates oxidative stress in the 1-methyl-4-phenyl-1,2,3,6tetrahydropyridine model of Parkinson's disease," Proceedings of the National Academy of Sciences of the United States of America, vol. 100, no. 10, pp. 6145-6150, 2003.

[29] R. Vilar, H. Coelho, E. Rodrigues et al., "Association of A313 G polymorphism (GSTP1*B) in the glutathioneS-transferase P1 gene with sporadic Parkinson's disease," European Journal of Neurology, vol. 14, no. 2, pp. 156-161, 2007.

[30] M. Singh, A. J. Khan, P. P. Shah, R. Shukla, V. K. Khanna, and D. Parmar, "Polymorphism in environment responsive genes and association with Parkinson disease," Molecular and Cellular Biochemistry, vol. 312, no. 1-2, pp. 131-138, 2008.

[31] D. B. Hancock, E. R. Martin, G. M. Mayhew et al., "Pesticide exposure and risk of Parkinson's disease: a family-based casecontrol study," BMC Neurology, vol. 8, article 6, 2008.

[32] V. Bonifati, "LRRK2 low-penetrance mutations (Gly2019Ser) and risk alleles (Gly2385Arg)_-linking familial and sporadic Parkinson's disease," Neurochemical Research, vol. 32, no. 10, pp. 1700-1708, 2007.

[33] J. A. Firestone, T. Smith-Weller, G. Franklin, P. Swanson, W. T. Longstreth Jr., and H. Checkoway, "Pesticides and risk of Parkinson disease: a population-based case-control study," Archives of Neurology, vol. 62, no. 1, pp. 91-95, 2005.

[34] S. Costello, M. Cockburn, J. Bronstein, X. Zhang, and B. Ritz, "Parkinson's disease and residential exposure to maneb and paraquat from agricultural applications in the central valley of California," American Journal of Epidemiology, vol. 169, no. 8, pp. 919-926, 2009.

[35] I. Baldi, A. Cantagrel, P. Lebailly et al., "Association between Parkinson's disease and exposure to pesticides in southwestern France," Neuroepidemiology, vol. 22, no. 5, pp. 305-310, 2003.

[36] A. S. Dhillon, G. L. Tarbutton, J. L. Levin et al., "Pesticide/environmental exposures and Parkinson's disease in East Texas," Journal of Agromedicine, vol. 13, no. 1, pp. 37-48, 2008.

[37] H. H. Liou, M. C. Tsai, C. J. Chen et al., "Environmental risk factors and Parkinson's disease: a case-control study in Taiwan," Neurology, vol. 48, no. 6, pp. 1583-1588, 1997.

[38] X. Li, J. Yin, C. M. Cheng, J. L. Sun, Z. Li, and Y. L. $\mathrm{Wu}$, "Paraquat induces selective dopaminergic nigrostriatal degeneration in aging C57BL/6 mice," Chinese Medical Journal, vol. 118, no. 16, pp. 1357-1361, 2005.

[39] A. I. Brooks, C. A. Chadwick, H. A. Gelbard, D. A. CorySlechta, and H. J. Federoff, "Paraquat elicited neurobehavioral syndrome caused by dopaminergic neuron loss," Brain Research, vol. 823, no. 1-2, pp. 1-10, 1999.
[40] T. Chanyachukul, K. Yoovathaworn, W. Thongsaard, S. Chongthammakun, P. Navasumrit, and J. Satayavivad, "Attenuation of paraquat-induced motor behavior and neurochemical disturbances by L-valine in vivo," Toxicology Letters, vol. 150, no. 3, pp. 259-269, 2004.

[41] P. Chen, Z. Chen, A. Li et al., "Catalytic metalloporphyrin protects against paraquat neurotoxicity in vivo," Biomedical and Environmental Sciences, vol. 21, no. 3, pp. 233-238, 2008.

[42] D. Litteljohn, E. Mangano, N. Shukla, and S. Hayley, "Interferon- $\gamma$ deficiency modifies the motor and co-morbid behavioral pathology and neurochemical changes provoked by the pesticide paraquat," Neuroscience, vol. 164, no. 4, pp. 1894-1906, 2009.

[43] Q. Chen, Y. Niu, R. Zhang et al., "The toxic influence of paraquat on hippocampus of mice: involvement of oxidative stress," NeuroToxicology, vol. 31, no. 3, pp. 310-316, 2010.

[44] E. N. Mangano, D. Litteljohn, R. So et al., "Interferon-gamma plays a crucial role in paraquat-induced neurodegeneration involving oxidative and pro-inflammatory pathways," Neurobiology of Aging. In press.

[45] M. Thiruchelvam, A. McCormack, E. K. Richfield et al., "Agerelated irreversible progressive nigrostriatal dopaminergic neurotoxicity in the paraquat and maneb model of the Parkinson's disease phenotype," European Journal of Neuroscience, vol. 18, no. 3, pp. 589-600, 2003.

[46] A. I. Rojo, C. Cavada, M. R. de Sagarra, and A. Cuadrado, "Chronic inhalation of rotenone or paraquat does not induce Parkinson's disease symptoms in mice or rats," Experimental Neurology, vol. 208, no. 1, pp. 120-126, 2007.

[47] K. Prasad, E. Tarasewicz, J. Mathew et al., "Toxicokinetics and toxicodynamics of paraquat accumulation in mouse brain," Experimental Neurology, vol. 215, no. 2, pp. 358-367, 2009.

[48] M. J. Kang, S. J. Gil, J. E. Lee, and H. C. Koh, "Selective vulnerability of the striatal subregions of C57BL/6 mice to paraquat," Toxicology Letters, vol. 195, no. 2-3, pp. 127-134, 2010.

[49] G. E. Meredith, P. K. Sonsalla, and M. F. Chesselet, "Animal models of Parkinson's disease progression," Acta Neuropathologica, vol. 115, no. 4, pp. 385-398, 2008.

[50] F. Cicchetti, J. Drouin-Ouellet, and R. E. Gross, "Environmental toxins and Parkinson's disease: what have we learned from pesticide-induced animal models?" Trends in Pharmacological Sciences, vol. 30, no. 9, pp. 475-483, 2009.

[51] J. T. Greenamyre, J. R. Cannon, R. Drolet, and P. G. Mastroberardino, "Lessons from the rotenone model of Parkinson's disease," Trends in Pharmacological Sciences, vol. 31, no. 4, pp. 141-142, 2010.

[52] V. N. Uversky, J. Li, and A. L. Fink, "Pesticides directly accelerate the rate of $\alpha$-synuclein fibril formation: a possible factor in Parkinson's disease," FEBS Letters, vol. 500, no. 3, pp. 105-108, 2001.

[53] A. B. Manning-Bog, A. L. McCormack, J. Li, V. N. Uversky, A. L. Fink, and D. A. Di Monte, "The herbicide paraquat causes up-regulation and aggregation of $\alpha$-synuclein in mice: paraquat and $\alpha$-synuclein," Journal of Biological Chemistry, vol. 277, no. 3, pp. 1641-1644, 2002.

[54] R. E. Drolet, J. R. Cannon, L. Montero, and J. T. Greenamyre, "Chronic rotenone exposure reproduces Parkinson's disease gastrointestinal neuropathology," Neurobiology of Disease, vol. 36, no. 1, pp. 96-102, 2009.

[55] V. N. Uversky, J. Li, K. Bower, and A. L. Fink, "Synergistic effects of pesticides and metals on the fibrillation of $\alpha$ synuclein: implications for Parkinson's disease," NeuroToxicology, vol. 23, no. 4-5, pp. 527-536, 2002. 
[56] J. Peng, L. Peng, F. F. Stevenson, S. R. Doctrow, and J. K. Andersen, "Iron and paraquat as synergistic environmental risk factors in sporadic Parkinson's disease accelerate agerelated neurodegeneration," Journal of Neuroscience, vol. 27, no. 26, pp. 6914-6922, 2007.

[57] J. Peng, F. F. Stevenson, M. L. Oo, and J. K. Andersen, "Ironenhanced paraquat-mediated dopaminergic cell death due to increased oxidative stress as a consequence of microglial activation," Free Radical Biology and Medicine, vol. 46, no. 2, pp. 312-320, 2009.

[58] M. Thiruchelvam, E. K. Richfield, R. B. Baggs, A. W. Tank, and D. A. Cory-Slechta, "The nigrostriatal dopaminergic system as a preferential target of repeated exposures to combined paraquat and maneb: Implications for Parkinson's disease," Journal of Neuroscience, vol. 20, no. 24, pp. 92079214, 2000.

[59] X. F. Wu, M. L. Block, W. Zhang et al., "The role of microglia in paraquat-induced dopaminergic neurotoxicity," Antioxidants and Redox Signaling, vol. 7, no. 5-6, pp. 654-661, 2005.

[60] H. Klintworth, G. Garden, and Z. Xia, "Rotenone and paraquat do not directly activate microglia or induce inflammatory cytokine release," Neuroscience Letters, vol. 462, no. 1, pp. 1-5, 2009.

[61] E. H. Wilson, W. Weninger, and C. A. Hunter, "Trafficking of immune cells in the central nervous system," Journal of Clinical Investigation, vol. 120, no. 5, pp. 1368-1379, 2010.

[62] C. K. Glass, K. Saijo, B. Winner, M. C. Marchetto, and F. H. Gage, "Mechanisms underlying inflammation in neurodegeneration," Cell, vol. 140, no. 6, pp. 918-934, 2010.

[63] T. Wyss-Coray and L. Mucke, "Inflammation in neurodegenerative disease- a double-edged sword," Neuron, vol. 35, no. 3, pp. 419-432, 2002.

[64] M. G. Tansey, M. K. McCoy, and T. C. Frank-Cannon, "Neuroinflammatory mechanisms in Parkinson's disease: potential environmental triggers, pathways, and targets for early therapeutic intervention," Experimental Neurology, vol. 208, no. 1, pp. 1-25, 2007.

[65] L. E. Goehler, A. Erisir, and R. P. A. Gaykema, "Neuralimmune interface in the rat area postrema," Neuroscience, vol. 140, no. 4, pp. 1415-1434, 2006.

[66] A. Suzumura, M. Sawada, and T. Takayanagi, "Production of interleukin-12 and expression of its receptors by murine microglia," Brain Research, vol. 787, no. 1, pp. 139-142, 1998.

[67] E. N. Benveniste, "Cytokine actions in the central nervous system," Cytokine and Growth Factor Reviews, vol. 9, no. 34, pp. 259-275, 1998.

[68] W. A. Banks, L. Ortiz, S. R. Plotkin, and A. J. Kastin, "Human interleukin (IL) $1 \alpha$, murine IL- $1 \alpha$ and murine IL$1 \beta$ are transported from blood to brain in the mouse by a shared saturable mechanism," Journal of Pharmacology and Experimental Therapeutics, vol. 259, no. 3, pp. 988-996, 1991.

[69] E. G. Gutierrez, W. A. Banks, and A. J. Kastin, "Murine tumor necrosis factor alpha is transported from blood to brain in the mouse," Journal of Neuroimmunology, vol. 47, no. 2, pp. 169-176, 1993.

[70] S. Rivest, "How circulating cytokines trigger the neural circuits that control the hypothalamic-pituitary-adrenal axis," Psychoneuroendocrinology, vol. 26, no. 8, pp. 761-788, 2001.

[71] B. Schobitz, J. M. H. M. Reul, and F. Holsboer, "The role of the hypothalamic-pituitary-adrenocortical system during inflammatory conditions," Critical Reviews in Neurobiology, vol. 8, no. 4, pp. 263-291, 1994.
[72] S. Nadeau and S. Rivest, "Effects of circulating tumor necrosis factor on the neuronal activity and expression of the genes encoding the tumor necrosis factor receptors (p55 and p75) in the rat brain: a view from the blood-brain barrier," Neuroscience, vol. 93, no. 4, pp. 1449-1464, 1999.

[73] V. Tancredi, G. D’Arcangelo, F. Grassi et al., "Tumor necrosis factor alters synaptic transmission in rat hippocampal slices," Neuroscience Letters, vol. 146, no. 2, pp. 176-178, 1992.

[74] F. Wuchert, D. Ott, S. Rafalzik, J. Roth, and R. Gerstberger, "Tumor necrosis factor- $\alpha$, interleukin- $\beta$ and nitric oxide induce calcium transients in distinct populations of cells cultured from the rat area postrema," Journal of Neuroimmunology, vol. 206, no. 1-2, pp. 44-51, 2009.

[75] K. Kamm, W. Vanderkolk, C. Lawrence, M. Jonker, and A. T. Davis, "The effect of traumatic brain injury upon the concentration and expression of interleukin-1beta and interleukin-10 in the rat," Journal of Trauma, vol. 60, no. 1, pp. 152-157, 2006.

[76] W. A. Banks, "Cytokines, CVSs, and the blood-brain-barrier," in Psychoneuroimmunology, R. Ader, D. L. Felten, and N. Cohen, Eds., pp. 483-498, Academic Press, New York, NY, USA, 2001.

[77] F. Clausen, A. Hånell, M. Björk et al., "Neutralization of interleukin- $1 \beta$ modifies the inflammatory response and improves histological and cognitive outcome following traumatic brain injury in mice," European Journal of Neuroscience, vol. 30, no. 3, pp. 385-396, 2009.

[78] B. H. Clausen, K. L. Lambertsen, A. A. Babcock, T. H. Holm, F. Dagnaes-Hansen, and B. Finsen, "Interleukin-1 beta and tumor necrosis factor-alpha are expressed by different subsets of microglia and macrophages after ischemic stroke in mice," Journal of Neuroinflammation, vol. 5, article 46, 2008.

[79] Y.-Q. Shen, G. Hebert, L.-Y. Lin et al., "Interleukine-1 $\beta$ and interleukine-6 levels in striatum and other brain structures after MPTP treatment: influence of behavioral lateralization," Journal of Neuroimmunology, vol. 158, no. 1-2, pp. 14-25, 2005.

[80] V. H. Perry, C. Cunningham, and C. Holmes, "Systemic infections and inflammation affect chronic neurodegeneration," Nature Reviews Immunology, vol. 7, no. 2, pp. 161-167, 2007.

[81] H. M. Gao, J. S. Hong, W. Zhang, and B. Liu, "Synergistic dopaminergic neurotoxicity of the pesticide rotenone and inflammogen lipopolysaccharide: relevance to the etiology of Parkinson's disease," Journal of Neuroscience, vol. 23, no. 4, pp. 1228-1236, 2003.

[82] E. N. Mangano and S. Hayley, "Inflammatory priming of the substantia nigra influences the impact of later paraquat exposure: neuroimmune sensitization of neurodegeneration," Neurobiology of Aging, vol. 30, no. 9, pp. 1361-1378, 2009.

[83] W. G. Kim, R. P. Mohney, B. Wilson, G. H. Jeohn, B. Liu, and J. S. Hong, "Regional difference in susceptibility to lipopolysaccharide-induced neurotoxicity in the rat brain: role of microglia," Journal of Neuroscience, vol. 20, no. 16, pp. 6309-6316, 2000.

[84] A. Castaño, A. J. Herrera, J. Cano, and A. Machado, "The degenerative effect of a single intranigral injection of LPS on the dopaminergic system is prevented by dexamethasone, and not mimicked by rh-TNF- $\alpha$ IL- $1 \beta$ IFN- $\gamma$," Journal of Neurochemistry, vol. 81, no. 1, pp. 150-157, 2002.

[85] Z. Ling, Y. Zhu, C. W. Tong, J. A. Snyder, J. W. Lipton, and P. M. Carvey, "Progressive dopamine neuron loss following supra-nigral lipopolysaccharide (LPS) infusion into rats 
exposed to LPS prenatally," Experimental Neurology, vol. 199, no. 2, pp. 499-512, 2006.

[86] B. K. Barlow, D. A. Cory-Slechta, E. K. Richfield, and M. Thiruchelvam, "The gestational environment and Parkinson's disease: evidence for neurodevelopmental origins of a neurodegenerative disorder," Reproductive Toxicology, vol. 23, no. 3, pp. 457-470, 2007.

[87] P. M. Carvey, Q. Chang, J. W. Lipton, and Z. Ling, "Prenatal exposure to the bacteriotoxin lipopolysaccharide leads to long-term losses of dopamine neurons in offspring: a potential, new model of Parkinson's disease," Frontiers in Bioscience, vol. 8, pp. s826-s837, 2003.

[88] Z. Ling, Q. A. Chang, C. W. Tong, S. E. Leurgans, J. W. Lipton, and P. M. Carvey, "Rotenone potentiates dopamine neuron loss in animals exposed to lipopolysaccharide prenatally," Experimental Neurology, vol. 190, no. 2, pp. 373-383, 2004.

[89] H. Hagberg, C. Mallard, and B. Jacobsson, "Role of cytokines in preterm labour and brain injury," British Journal of Obstetrics and Gynaecology, vol. 112, supplement 1, pp. 1618, 2005.

[90] E. Ribiani, A. Rosati, M. Romanelli, L. Cruciani, F. Incalza, and G. C. Di Renzo, "Perinatal infections and cerebral palsy," Minerva Ginecologica, vol. 59, no. 2, pp. 151-157, 2007.

[91] H. Anisman, Z. Merali, and S. Hayley, "Neurotransmitter, peptide and cytokine processes in relation to depressive disorder: comorbidity between depression and neurodegenerative disorders," Progress in Neurobiology, vol. 85, no. 1, pp. $1-74,2008$.

[92] S. Hayley, E. Mangano, M. Strickland, and H. Anisman, "Lipopolysaccharide and a social stressor influence behaviour, corticosterone and cytokine levels: divergent actions in cyclooxygenase-2 deficient mice and wild type controls," Journal of Neuroimmunology, vol. 197, no. 1, pp. 29-36, 2008.

[93] V. Basic Kes, A. M. Simundic, N. Nikolac, E. Topic, and V. Demarin, "Pro-inflammatory and anti-inflammatory cytokines in acute ischemic stroke and their relation to early neurological deficit and stroke outcome," Clinical Biochemistry, vol. 41, no. 16-17, pp. 1330-1334, 2008.

[94] B. Brodacki, J. Staszewski, B. Toczyłowska et al., "Serum interleukin (IL-2, IL-10, IL-6, IL-4), TNF $\alpha$, and INF $\gamma$ concentrations are elevated in patients with atypical and idiopathic parkinsonism," Neuroscience Letters, vol. 441, no. 2, pp. 158-162, 2008.

[95] J. C. Goodman, M. Van, S. P. Gopinath, and C. S. Robertson, "Pro-inflammatory and pro-apoptotic elements of the neuroinflammatory response are activated in traumatic brain injury," Acta neurochirurgica. Supplement, vol. 102, pp. 437439, 2008.

[96] M. Reale, C. Iarlori, A. Thomas et al., "Peripheral cytokines profile in Parkinson's disease," Brain, Behavior, and Immunity, vol. 23, no. 1, pp. 55-63, 2009.

[97] A. J. Bruce, W. Boling, M. S. Kindy et al., "Altered neuronal and microglial responses to excitotoxic and ischemic brain injury in mice lacking TNF receptors," Nature Medicine, vol. 2, no. 7, pp. 788-794, 1996.

[98] R. J. Rogers, J. M. Monnier, and H. S. Nick, "Tumor necrosis factor- $\alpha$ selectively induces MnSOD expression via mitochondria-to-nucleus signaling, whereas interleukin$1 \beta$ utilizes an alternative pathway," Journal of Biological Chemistry, vol. 276, no. 23, pp. 20419-20427, 2001.

[99] G. B. T. von Boyen, M. Steinkamp, I. Geerling et al., "Proinflammatory cytokines induce neurotrophic factor expression in enteric glia: a key to the regulation of epithelial apoptosis in Crohn's disease," Inflammatory Bowel Diseases, vol. 12, no. 5, pp. 346-354, 2006.

[100] F. C. Barone, B. Arvin, R. F. White et al., "Tumor necrosis factor- $\alpha$ : a mediator of focal ischemic brain injury," Stroke, vol. 28, no. 6, pp. 1233-1244, 1997.

[101] F. C. Barone, R. F. White, P. A. Spera et al., "Ischemic preconditioning and brain tolerance: temporal histological and functional outcomes, protein synthesis requirement, and interleukin-1 receptor antagonist and early gene expression," Stroke, vol. 29, no. 9, pp. 1937-1950, 1998.

[102] J. Kawanokuchi, T. Mizuno, H. Takeuchi et al., "Production of interferon- $\gamma$ by microglia," Multiple Sclerosis, vol. 12, no. 5, pp. 558-564, 2006.

[103] K. Schroder, P. J. Hertzog, T. Ravasi, and D. A. Hume, "Interferon- $\gamma$ : an overview of signals, mechanisms and functions," Journal of Leukocyte Biology, vol. 75, no. 2, pp. 163-189, 2004.

[104] T. Decker, M. Müller, and S. Stockinger, "The Yin and Yang of type I interferon activity in bacterial infection," Nature Reviews Immunology, vol. 5, no. 9, pp. 675-687, 2005.

[105] M. Rayamajhi, J. Humann, K. Penheiter, K. Andreasen, and L. L. Lenz, "Induction of IFN $-\alpha \beta$ enables Listeria monocytogenes to suppress macrophage activation by IFN$\gamma$," Journal of Experimental Medicine, vol. 207, no. 2, pp. 327$337,2010$.

[106] P. Sarasombath, K. Sumida, and D. A. Kaku, "Parkinsonism associated with interferon alpha therapy for chronic myelogenous leukemia," Hawaii Medical Journal, vol. 61, no. 3, pp. 48-57, 2002.

[107] M. Kajihara, S. Montagnese, P. Khanna et al., "Parkinsonism in patients with chronic hepatitis $\mathrm{C}$ treated with interferon$\alpha 2 \mathrm{~b}$ : a report of two cases," European Journal of Gastroenterology and Hepatology, vol. 22, no. 5, pp. 628-631, 2010.

[108] T. Yamada, M. A. Horisberger, N. Kawaguchi, I. Moroo, and T. Toyoda, "Immunohistochemistry using antibodies to $\alpha$ interferon and its induced protein, MxA, in Alzheimer's and Parkinson's disease brain tissues," Neuroscience Letters, vol. 181, no. 1-2, pp. 61-64, 1994.

[109] T. Yamada, "Further observations on MxA-positive Lewy bodies in Parkinson's disease brain tissues," Neuroscience Letters, vol. 195, no. 1, pp. 41-44, 1995.

[110] M. P. Mount, A. Lira, D. Grimes et al., "Involvement of interferon- $\gamma$ in microglial-mediated loss of dopaminergic neurons," Journal of Neuroscience, vol. 27, no. 12, pp. 33283337, 2007.

[111] I. E. Gribova, B. B. Gnedenko, V. V. Poleshchuk, and S. G. Morozov, "Content of interferon-gamma, alpha tumor necrosis factor and autoantibodies to them in blood serum during Parkinson's disease," Biomeditsinskaya Khimiya, vol. 49, no. 2, pp. 208-212, 2003.

[112] S. Hunot, N. Dugas, B. Faucheux et al., "FceRII/CD23 is expressed in Parkinson's disease and induces, in vitro, production of nitric oxide and tumor necrosis factor- $\alpha$ in glial cells," Journal of Neuroscience, vol. 19, no. 9, pp. 34403447, 1999.

[113] M. Mogi, T. Kondo, Y. Mizuno, and T. Nagatsu, "p53 protein, interferon $-\gamma$, and NF- $\kappa$ B levels are elevated in the parkinsonian brain," Neuroscience Letters, vol. 414, no. 1, pp. 94-97, 2007.

[114] I. Mizuta, M. Nishimura, E. Mizuta et al., "Relation between the high production related allele of the interferon- $\gamma$ (IFN$\gamma$ ) gene and age at onset of idiopathic Parkinson's disease in Japan," Journal of Neurology Neurosurgery and Psychiatry, vol. 71, no. 6, pp. 818-819, 2001. 
[115] B. Widner, F. Leblhuber, and D. Fuchs, "Increased neopterin production and tryptophan degradation in advanced Parkinson's disease," Journal of Neural Transmission, Supplement, vol. 109, no. 2, pp. 181-189, 2002.

[116] N. Kawaguchi, T. Yamada, M. Takahashi, and T. Hattori, "Expression of MxA mRNA in peripheral blood mononuclear cells in Parkinson's disease," Parkinsonism and Related Disorders, vol. 5, no. 1-2, pp. 43-47, 1999.

[117] M. D’Amelio, P. Ragonese, L. Morgante et al., "Tumor diagnosis preceding Parkinson's disease: a case-control study," Movement Disorders, vol. 19, no. 7, pp. 807-811, 2004.

[118] T. Mizuno, G. Zhang, H. Takeuchi et al., "Interferon- $\gamma$ directly induces neurotoxicity through a neuron specific, calcium-permeable complex of IFN- $\gamma$ receptor and AMPA GluR1 receptor," FASEB Journal, vol. 22, no. 6, pp. 17971806, 2008.

[119] L. B. Moran, D. C. Duke, F. E. Tarkheimer, R. B. Banati, and M. B. Graeber, "Towards a transcriptome definition of microglial cells," Neurogenetics, vol. 5, no. 2, pp. 95-108, 2004.

[120] R. B. Rock, S. Hu, A. Deshpande et al., "Transcriptional response of human microglial cells to interferon- $\gamma$," Genes and Immunity, vol. 6, no. 8, pp. 712-719, 2005.

[121] I. Kurkowska-Jastrzebska, A. Wrońska, M. Kohutnicka, A. Członkowski, and A. Członkowska, "MHC class II positive microglia and lymphocytic infiltration are present in the substantia nigra and striatum in mouse model of Parkinson's disease," Acta Neurobiologiae Experimentalis, vol. 59, no. 1, pp. 1-8, 1999.

[122] K. Imamura, N. Hishikawa, M. Sawada, T. Nagatsu, M. Yoshida, and Y. Hashizume, "Distribution of major histocompatibility complex class II-positive microglia and cytokine profile of Parkinson's disease brains," Acta Neuropathologica, vol. 106, no. 6, pp. 518-526, 2003.

[123] D. A. Loeffler, D. M. Camp, and S. B. Conant, "Complement activation in the Parkinson's disease substantia nigra: an immunocytochemical study," Journal of Neuroinflammation, vol. 3, article 29, 2006.

[124] V. Brochard, B. Combadière, A. Prigent et al., "Infiltration of CD4+ lymphocytes into the brain contributes to neurodegeneration in a mouse model of Parkinson disease," Journal of Clinical Investigation, vol. 119, no. 1, pp. 182-192, 2009.

[125] K. R. Ju, H. S. Kim, J. H. Kim, N. Y. Lee, and C. K. Park, "Retinal glial cell responses and Fas/FasL activation in rats with chronic ocular hypertension," Brain Research, vol. 1122, no. 1, pp. 209-221, 2006.

[126] M. Mir, V. J. Asensio, L. Tolosa et al., "Tumor necrosis factor alpha and interferon gamma cooperatively induce oxidative stress and motoneuron death in rat spinal cord embryonic explants," Neuroscience, vol. 162, no. 4, pp. 959-971, 2009.

[127] M. Jana, X. Liu, S. Koka, S. Ghosh, T. M. Petro, and K. Pahan, "Ligation of CD40 stimulates the induction of nitric-oxide synthase in microglial cells," Journal of Biological Chemistry, vol. 276, no. 48, pp. 44527-44533, 2001.

[128] M. Zamanian-Daryoush, T. H. Mogensen, J. A. DiDonato, and B. R. G. Williams, "NF- $\kappa$ B activation by doublestranded-RNA-activated protein kinase $(\mathrm{PKR})$ is mediated through NF- $\kappa \mathrm{B}$-inducing kinase and I $\kappa \mathrm{B}$ kinase," Molecular and Cellular Biology, vol. 20, no. 4, pp. 1278-1290, 2000.

[129] E. Esposito, A. Iacono, C. Muià et al., "Signal transduction pathways involved in protective effects of melatonin in C6 glioma cells," Journal of Pineal Research, vol. 44, no. 1, pp. 78-87, 2008.
[130] L. B. Moran, D. C. Duke, and M. B. Graeber, "The microglial gene regulatory network activated by interferon-gamma," Journal of Neuroimmunology, vol. 183, no. 1-2, pp. 1-6, 2007.

[131] Y. Baba, A. Kuroiwa, R. J. Uitti, Z. K. Wszolek, and T. Yamada, "Alterations of T-lymphocyte populations in Parkinson disease," Parkinsonism and Related Disorders, vol. 11, no. 8, pp. 493-498, 2005.

[132] J. Durbin, L. Doughty, K. Nguyen, M. Caligiuri, J. van Deusen, and C. Biron, "The role of STAT1 in viral sensitization to LPS," Journal of Endotoxin Research, vol. 9, no. 5, pp. 313-316, 2003.

[133] L. Qian, M. L. Block, S. J. Wei et al., "Interleukin-10 protects lipopolysaccharide-induced neurotoxicity in primary midbrain cultures by inhibiting the function of NADPH oxidase," Journal of Pharmacology and Experimental Therapeutics, vol. 319, no. 1, pp. 44-52, 2006.

[134] L. C. Johnston, X. Su, K. Maguire-Zeiss et al., "Human interleukin-10 gene transfer is protective in a rat model of Parkinson's disease," Molecular Therapy, vol. 16, no. 8, pp. 1392-1399, 2008.

[135] A. Quesada, B. Y. Lee, and P. E. Micevych, "PI3 kinase/Akt activation mediates estrogen and IGF-1 nigral DA neuronal neuroprotection against a unilateral rat model of Parkinson's disease," Developmental Neurobiology, vol. 68, no. 5, pp. 632644, 2008.

[136] R. Meller, S. L. Stevens, M. Minami et al., "Neuroprotection by osteopontin in stroke," Journal of Cerebral Blood Flow and Metabolism, vol. 25, no. 2, pp. 217-225, 2005.

[137] J. Iczkiewicz, M. J. Jackson, L. A. Smith, S. Rose, and P. Jenner, "Osteopontin expression in substantia nigra in MPTP-treated primates and in Parkinson's disease," Brain Research, vol. 1118, no. 1, pp. 239-250, 2006.

[138] W. Maetzler, D. Berg, N. Schalamberidze et al., "Osteopontin is elevated in Parkinson's disease and its absence leads to reduced neurodegeneration in the MPTP model," Neurobiology of Disease, vol. 25, no. 3, pp. 473-482, 2007.

[139] S. Hashioka, A. Klegeris, C. Schwab, and P. L. McGeer, "Interferon- $\gamma$-dependent cytotoxic activation of human astrocytes and astrocytoma cells," Neurobiology of Aging, vol. 30, no. 12, pp. 1924-1935, 2009.

[140] S. Hashioka, A. Klegeris, H. Qing, and P. L. McGeer, "STAT3 inhibitors attenuate interferon- $\gamma$-induced neurotoxicity and inflammatory molecule production by human astrocytes," Neurobiology of Disease. In press.

[141] H. J. Ryu, J.-E. Kim, M.-J. Kim et al., “The protective effects of interleukin-18 and interferon- $\gamma$ on neuronal damages in the rat hippocampus following status epilepticus," Neuroscience, vol. 170, no. 3, pp. 711-721, 2010.

[142] G. Ramírez, R. Toro, H. Döbeli, and R. von Bernhardi, "Protection of rat primary hippocampal cultures from $\mathrm{A} \beta$ cytotoxicity by pro-inflammatory molecules is mediated by astrocytes," Neurobiology of Disease, vol. 19, no. 1-2, pp. 243254, 2005.

[143] N. A. Thornberry, H. G. Bull, J. R. Calaycay et al., "A novel heterodimeric cysteine protease is required for interleukin$1 \beta$ processing in monocytes," Nature, vol. 356, no. 6372, pp. 768-774, 1992.

[144] C. A. Dinarello, “Biology of interleukin 1," FASEB Journal, vol. 2, no. 2, pp. 108-115, 1988.

[145] N. J. Rothwell and S. J. Hopkins, "Cytokines and the nervous system II: actions and mechanisms of action," Trends in Neurosciences, vol. 18, no. 3, pp. 130-136, 1995. 
[146] A. Eigler, B. Sinha, G. Hartmann, and S. Endres, "Taming TNF: strategies to restrain this proinflammatory cytokine," Immunology Today, vol. 18, no. 10, pp. 487-492, 1997.

[147] S. Mandel, E. Grünblatt, and M. B. H. Youdim, “cDNA microarray to study gene expression of dopaminergic neurodegeneration and neuroprotection in MPTP and 6-hydroxydopamine models: implications for idiopathic Parkinson's disease," Journal of Neural Transmission, Supplement, no. 60, pp. 117-124, 2000.

[148] M. J. Bian, L. M. Li, M. Yu, J. Fei, and F. Huang, "Elevated interleukin- $1 \beta$ induced by 1 -methyl-4-phenyl-1,2,3,6tetrahydropyridine aggravating dopaminergic neurodegeneration in old male mice," Brain Research, vol. 1302, pp. 256264, 2009.

[149] F. Jin, Q. Wu, Y. F. Lu, Q. H. Gong, and J. S. Shi, "Neuroprotective effect of resveratrol on 6-OHDA-induced Parkinson's disease in rats," European Journal of Pharmacology, vol. 600, no. 1-3, pp. 78-82, 2008.

[150] J. B. Koprich, C. Reske-Nielsen, P. Mithal, and O. Isacson, "Neuroinflammation mediated by IL- $1 \beta$ increases susceptibility of dopamine neurons to degeneration in an animal model of Parkinson's disease," Journal of Neuroinflammation, vol. 5, article 8, 2008.

[151] M. C. Pott Godoy, R. Tarelli, C. C. Ferrari, M. I. Sarchi, and F. J. Pitossi, "Central and systemic IL-1 exacerbates neurodegeneration and motor symptoms in a model of Parkinson's disease," Brain, vol. 131, no. 7, pp. 1880-1894, 2008.

[152] M. C. Pott Godoy, C. C. Ferrari, and F. J. Pitossi, "Nigral neurodegeneration triggered by striatal AdIL-1 administration can be exacerbated by systemic IL-1 expression," Journal of Neuroimmunology, vol. 222, no. 1-2, pp. 29-39, 2010.

[153] J. Wang, K. S. Bankiewicz, R. J. Plunkett, and E. H. Oldfield, "Intrastriatal implantation of interleukin-1. Reduction of parkinsonism in rats by enhancing neuronal sprouting from residual dopaminergic neurons in the ventral tegmental area of the midbrain," Journal of Neurosurgery, vol. 80, no. 3, pp. 484-490, 1994.

[154] J. Saura, M. Parés, J. Bové et al., "Intranigral infusion of interleukin- $1 \beta$ activates astrocytes and protects from subsequent 6-hydroxydopamine neurotoxicity," Journal of Neurochemistry, vol. 85, no. 3, pp. 651-661, 2003.

[155] K. Sriram, J. M. Matheson, S. A. Benkovic, D. B. Miller, M. I. Luster, and J. P. O'Callaghan, "Mice deficient in TNF receptors are protected against dopaminergic neurotoxicity: implications for Parkinson's disease," FASEB Journal, vol. 16, no. 11, pp. 1474-1476, 2002.

[156] B. Ferger, A. Leng, A. Mura, B. Hengerer, and J. Feldon, "Genetic ablation of tumor necrosis factor-alpha (TNF- $\alpha$ ) and pharmacological inhibition of TNF-synthesis attenuates MPTP toxicity in mouse striatum," Journal of Neurochemistry, vol. 89, no. 4, pp. 822-833, 2004.

[157] E. Rousselet, J. Callebert, K. Parain et al., "Role of TNF- $\alpha$ receptors in mice intoxicated with the parkinsonian toxin MPTP," Experimental Neurology, vol. 177, no. 1, pp. 183-192, 2002.

[158] A. L. de Lella Ezcurra, M. Chertoff, C. Ferrari, M. Graciarena, and F. Pitossi, "Chronic expression of low levels of tumor necrosis factor- $\alpha$ in the substantia nigra elicits progressive neurodegeneration, delayed motor symptoms and microglia/macrophage activation," Neurobiology of Disease, vol. 37, no. 3, pp. 630-640, 2010.
[159] M. K. McCoy, K. A. Ruhn, T. N. Martinez, F. E. McAlpine, A. Blesch, and M. G. Tansey, "Intranigral lentiviral delivery of dominant-negative TNF attenuates neurodegeneration and behavioral deficits in hemiparkinsonian rats," Molecular Therapy, vol. 16, no. 9, pp. 1572-1579, 2008.

[160] P. C. Lucas, L. M. McAllister-Lucas, and G. Nunez, "NF- $\kappa$ B in signaling in lymphocytes: a new cast of characters," Journal of Cell Science, vol. 117, no. 1, pp. 31-39, 2004.

[161] M. E. Poynter, R. Cloots, T. van Woerkom et al., "NF- $\kappa B$ activation in airways modulates allergic inflammation but not hyperresponsiveness," Journal of Immunology, vol. 173, no. 11, pp. 7003-7009, 2004.

[162] J. P. Konsman, V. Tridon, and R. Dantzer, "Diffusion and action of intracerebroventricularly injected interleukin-1 in the CNS," Neuroscience, vol. 101, no. 4, pp. 957-967, 2000.

[163] M. P. Mattson, "NF- $\kappa \mathrm{B}$ in the survival and plasticity of neurons," Neurochemical Research, vol. 30, no. 6-7, pp. 883893, 2005.

[164] M. Hartlage-Rübsamen, R. Lemke, and R. Schliebs, "Interleukin- $1 \beta$, inducible nitric oxide synthase, and nuclear factor- $\kappa \mathrm{B}$ are induced in morphologically distinct microglia after rat hippocampal lipopolysaccharide/interferon- $\gamma$ injection," Journal of Neuroscience Research, vol. 57, no. 3, pp. 388-398, 1999.

[165] K. Pahan, F. G. Sheikh, X. Liu, S. Hilger, M. McKinney, and T. M. Petro, "Induction of nitric-oxide synthase and activation of NF- $\kappa$ B by interleukin-12 p40 in microglial cells," Journal of Biological Chemistry, vol. 276, no. 11, pp. 7899-7905, 2001.

[166] J. L. M. Madrigal, B. García-Bueno, J. R. Caso, B. G. PérezNievas, and J. C. Leza, "Stress-induced oxidative changes in brain," CNS and Neurological Disorders-Drug Targets, vol. 5, no. 5, pp. 561-568, 2006.

[167] L. Minghetti, "Cyclooxygenase-2 (COX-2) in inflammatory and degenerative brain diseases," Journal of Neuropathology and Experimental Neurology, vol. 63, no. 9, pp. 901-910, 2004.

[168] T. G. Brock, R. W. McNish, and M. Peters-Golden, "Arachidonic acid is preferentially metabolized by cyclooxygenase2 to prostacyclin and prostaglandin E," Journal of Biological Chemistry, vol. 274, no. 17, pp. 11660-11666, 1999.

[169] N. V. Chandrasekharan, H. Dai, K. L.T. Roos et al., "COX3 , a cyclooxygenase-1 variant inhibited by acetaminophen and other analgesic/antipyretic drugs: cloning, structure, and expression," Proceedings of the National Academy of Sciences of the United States of America, vol. 99, no. 21, pp. 13926-13931, 2002.

[170] N. M. Davies, R. L. Good, K. A. Roupe, and J. A. Yáñez, "Cyclooxygenase-3: axiom, dogma, anomaly, enigma or splice error?-Not as easy as 1, 2, 3," Journal of Pharmacy and Pharmaceutical Sciences, vol. 7, no. 2, pp. 217-226, 2004.

[171] J. W. Phillis, L. A. Horrocks, and A. A. Farooqui, "Cyclooxygenases, lipoxygenases, and epoxygenases in CNS: their role and involvement in neurological disorders," Brain Research Reviews, vol. 52, no. 2, pp. 201-243, 2006.

[172] S. B. Appleby, A. Ristimaki, K. Neilson, K. Narko, and T. Hla, "Structure of the human cyclo-oxygenase-2 gene," Biochemical Journal, vol. 302, no. 3, pp. 723-727, 1994.

[173] J. K. Elmquist, C. D. Breder, J. E. Sherin et al., "Intravenous lipopolysaccharide induces cyclooxygenase 2-like immunoreactivity in rat brain perivascular microglia and meningeal macrophages," Journal of Comparative Neurology, vol. 381, no. 2, pp. 119-128, 1997. 
[174] R. Vijitruth, M. Liu, D. Y. Choi, X. V. Nguyen, R. L. Hunter, and G. Bing, "Cyclooxygenase-2 mediates microglial activation and secondary dopaminergic cell death in the mouse MPTP model of Parkinson's disease," Journal of Neuroinflammation, vol. 3, article 6, 2006.

[175] C. Knott, G. Stern, and G. P. Wilkin, "Inflammatory regulators in Parkinson's disease: iNOS, lipocortin-1, and cyclooxygenases-1 and -2," Molecular and Cellular Neuroscience, vol. 16, no. 6, pp. 724-739, 2000.

[176] P. Teismann, K. Tieu, D. K. Choi et al., "Cyclooxygenase-2 is instrumental in Parkinson's disease neurodegeneration," Proceedings of the National Academy of Sciences of the United States of America, vol. 100, no. 9, pp. 5473-5478, 2003.

[177] Z. H. Feng, T. G. Wang, D. D. Li et al., "Cyclooxygenase2-deficient mice are resistant to 1-methyl-4-phenyl1, 2, 3, 6-tetrahydropyridine-induced damage of dopaminergic neurons in the substantia nigra," Neuroscience Letters, vol. 329, no. 3, pp. 354-358, 2002.

[178] R. Sánchez-Pernaute, A. Ferree, O. Cooper, M. Yu, A. L. Brownell, and O. Isacson, "Selective COX-2 inhibition prevents progressive dopamine neuron degeneration in a rat model of Parkinson's disease," Journal of Neuroinflammation, vol. 1, no. 1, article 6, 2004.

[179] W. Yang, E. Tiffany-Castiglioni, M.-Y. Lee, and I.-H. Son, "Paraquat induces cyclooxygenase-2 (COX-2) implicated toxicity in human neuroblastoma SH-SY5Y cells," Toxicology Letters, vol. 199, no. 3, pp. 239-246, 2010.

[180] D. Litteljohn, E. N. Mangano, and S. Hayley, "Cyclooxygenase-2 deficiency modifies the neurochemical effects, motor impairment and co-morbid anxiety provoked by paraquat administration in mice," European Journal of Neuroscience, vol. 28, no. 4, pp. 707-716, 2008.

[181] M. Asanuma, S. Nishibayashi-Asanuma, I. Miyazaki, M. Kohno, and N. Ogawa, "Neuroprotective effects of nonsteroidal anti-inflammatory drugs by direct scavenging of nitric oxide radicals," Journal of Neurochemistry, vol. 76, no. 6, pp. 1895-1904, 2001.

[182] D. Costa, L. Moutinho, J. L. F. C. Lima, and E. Fernandes, "Antioxidant activity and inhibition of human neutrophil oxidative burst mediated by arylpropionic acid non-steroidal anti-inflammatory drugs," Biological and Pharmaceutical Bulletin, vol. 29, no. 8, pp. 1659-1670, 2006.

[183] H. Chen, E. Jacobs, M. A. Schwarzschild et al., "Nonsteroidal antiinflammatory drug use and the risk for Parkinson's disease," Annals of Neurology, vol. 58, no. 6, pp. 963-967, 2005.

[184] M. A. Hernán, G. Logroscino, and L. A. G. Rodríguez, "Nonsteroidal anti-inflammatory drugs and the incidence of Parkinson disease," Neurology, vol. 66, no. 7, pp. 1097-1099, 2006.

[185] A. D. Wahner, J. M. Bronstein, Y. M. Bordelon, and B. Ritz, "Nonsteroidal anti-inflammatory drugs may protect against Parkinson disease," Neurology, vol. 69, no. 19, pp. 1836-1842, 2007.

[186] T. G. Ton, S. R. Heckbert, W. T. Longstreth Jr. et al., "Nonsteroidal anti-inflammatory drugs and risk of Parkinson's disease," Movement Disorders, vol. 21, no. 7, pp. 964-969, 2006.

[187] M. Bornebroek, L. M. L. de Lau, M. D. M. Haag et al., "Nonsteroidal anti-inflammatory drugs and the risk of Parkinson disease," Neuroepidemiology, vol. 28, no. 4, pp. 193-196, 2007.
[188] M. Etminan, B. C. Carleton, and A. Samii, "Non-steroidal anti-inflammatory drug use and the risk of Parkinson disease: a retrospective cohort study," Journal of Clinical Neuroscience, vol. 15, no. 5, pp. 576-577, 2008.

[189] J. J. Gagne and M. C. Power, "Anti-inflammatory drugs and risk of Parkinson disease: a meta-analysis," Neurology, vol. 74, no. 12, pp. 995-1002, 2010.

[190] T. Kawano, J. Anrather, P. Zhou et al., "Prostaglandin E2 EP1 receptors: downstream effectors of COX-2 neurotoxicity," Nature Medicine, vol. 12, no. 2, pp. 225-229, 2006.

[191] E. Carrasco, D. Casper, and P. Werner, "PGE2 receptor EP1 renders dopaminergic neurons selectively vulnerable to lowlevel oxidative stress and direct PGE2 neurotoxicity," Journal of Neuroscience Research, vol. 85, no. 14, pp. 3109-3117, 2007.

[192] F. S. Shie, K. S. Montine, R. M. Breyer, and T. J. Montine, "Microglial EP2 is critical to neurotoxicity from activated cerebral innate immunity," GLIA, vol. 52, no. 1, pp. 70-77, 2005.

[193] V. Vichai, C. Suyarnsesthakorn, D. Pittayakhajonwut, K. Sriklung, and K. Kirtikara, "Positive feedback regulation of COX2 expression by prostaglandin metabolites," Inflammation Research, vol. 54, no. 4, pp. 163-172, 2005.

[194] B. Poligone and A. S. Baldwin, "Positive and negative regulation of NF- $\kappa$ B by COX-2. Roles of different prostaglandins," Journal of Biological Chemistry, vol. 276, no. 42, pp. 3865838664, 2001.

[195] A. Nadjar, V. Tridon, M. J. May et al., "NFאB activates in vivo the synthesis of inducible Cox-2 in the brain," Journal of Cerebral Blood Flow and Metabolism, vol. 25, no. 8, pp. 10471059, 2005.

[196] T. Wang, Z. Pei, W. Zhang et al., "MPP+-induced COX2 activation and subsequent dopaminergic neurodegeneration," FASEB Journal, vol. 19, no. 9, pp. 1134-1136, 2005.

[197] S. Hunot, M. Vila, P. Teismann et al., "JNK-mediated induction of cyclooxygenase 2 is required for neurodegeneration in a mouse model of Parkinson's disease," Proceedings of the National Academy of Sciences of the United States of America, vol. 101, no. 2, pp. 665-670, 2004.

[198] Y. Wang, Y. Zhang, Z. Wei et al., "JNK inhibitor protects dopaminergic neurons by reducing COX-2 expression in the MPTP mouse model of subacute Parkinson's disease," Journal of the Neurological Sciences, vol. 285, no. 1-2, pp. 172-177, 2009.

[199] J. Peng, X. O. Mao, F. F. Stevenson, M. Hsu, and J. K. Andersen, "The herbicide paraquat induces dopaminergic nigral apoptosis through sustained activation of the JNK pathway," Journal of Biological Chemistry, vol. 279, no. 31, pp. 32626-32632, 2004.

[200] W.-S. Choi, G. Abel, H. Klintworth, R. A. Flavell, and Z. Xia, "JNK3 mediates paraquat-and rotenone-induced dopaminergic neuron death," Journal of Neuropathology and Experimental Neurology, vol. 69, no. 5, pp. 511-520, 2010.

[201] M. Vázquez-Claverie, P. Garrido-Gil, W. San Sebastián et al., "1-methyl-4-phenyl-1,2,3,6-tetrahydropyridine (MPTP) does not elicit long-lasting increases in cyclooxygenase-2 expression in dopaminergic neurons of monkeys," Journal of Neuropathology and Experimental Neurology, vol. 68, no. 1, pp. 26-36, 2009.

[202] J. D. Boyd, H. Jang, K. R. Shepherd et al., "Response to 1methyl-4-phenyl-1,2,3,6-tetrahydropyridine (MPTP) differs in mouse strains and reveals a divergence in JNK signaling and COX-2 induction prior to loss of neurons in the substantia nigra pars compacta," Brain Research, vol. 1175, no. 1, pp. 107-116, 2007. 
[203] L. McCullough, L. Wu, N. Haughey et al., "Neuroprotective function of the PGE2 EP2 receptor in cerebral ischemia," Journal of Neuroscience, vol. 24, no. 1, pp. 257-268, 2004.

[204] A. S. Ahmad, H. Zhuang, V. Echeverria, and S. Doré, "Stimulation of prostaglandin EP2 receptors prevents NMDAinduced excitotoxicity," Journal of Neurotrauma, vol. 23, no. 12, pp. 1895-1903, 2006.

[205] V. Echeverria, A. Clerman, and S. Doré, "Stimulation of PGE2 receptors EP2 and EP4 protects cultured neurons against oxidative stress and cell death following $\beta$-amyloid exposure," European Journal of Neuroscience, vol. 22, no. 9, pp. 2199-2206, 2005.

[206] E. Carrasco, P. Werner, and D. Casper, "Prostaglandin receptor EP2 protects dopaminergic neurons against 6-OHDAmediated low oxidative stress," Neuroscience Letters, vol. 441, no. 1, pp. 44-49, 2008.

[207] J. Shi, J. Johansson, N. S. Woodling, Q. Wang, T. J. Montine, and K. Andreasson, "The prostaglandin E2 E-prostanoid 4 receptor exerts anti-inflammatory effects in brain innate immunity," Journal of Immunology, vol. 184, no. 12, pp. 7207-7218, 2010

[208] S. F. Tzeng, H. Y. Hsiao, and O. T. Mak, "Prostaglandins and cyclooxygenases in glial cells during brain inflammation," Current Drug Targets: Inflammation and Allergy, vol. 4, no. 3, pp. 335-340, 2005.

[209] A. J. Hutchinson, C. L. Chou, D. D. Israel, W. Xu, and J. W. Regan, "Activation of EP2 prostanoid receptors in human glial cell lines stimulates the secretion of BDNF," Neurochemistry International, vol. 54, no. 7, pp. 439-446, 2009.

[210] N. G. Bazan, V. L. Marcheselli, and K. Cole-Edwards, "Brain response to injury and neurodegeneration: endogenous neuroprotective signaling," Annals of the New York Academy of Sciences, vol. 1053, pp. 137-147, 2005.

[211] A. A. Farooqui, L. A. Horrocks, and T. Farooqui, "Modulation of inflammation in brain: a matter of fat," Journal of Neurochemistry, vol. 101, no. 3, pp. 577-599, 2007. 


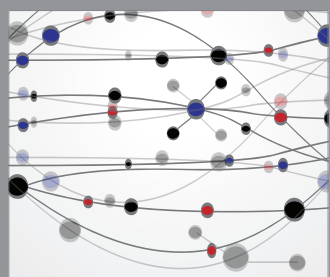

The Scientific World Journal
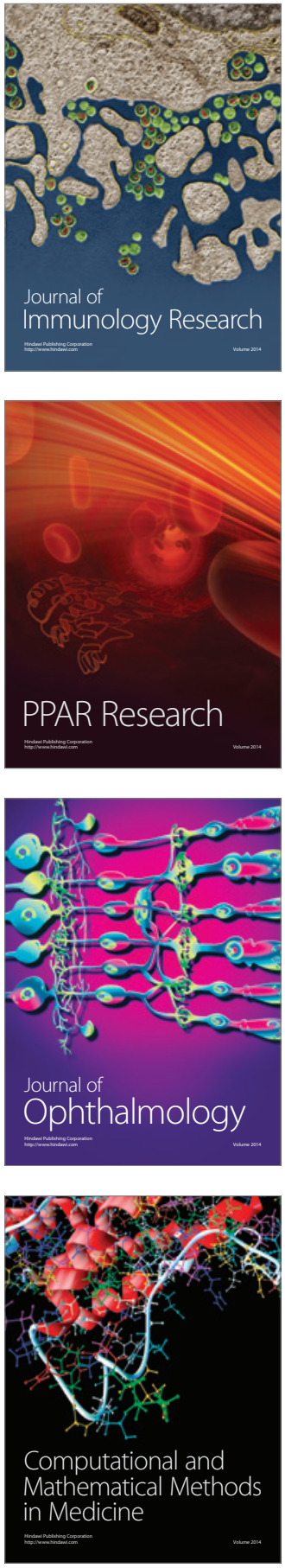

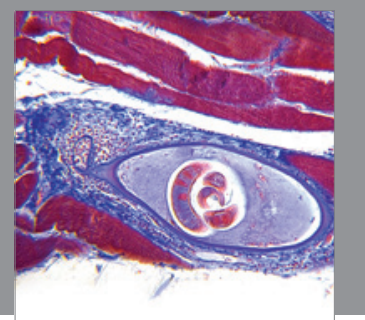

Gastroenterology

Research and Practice
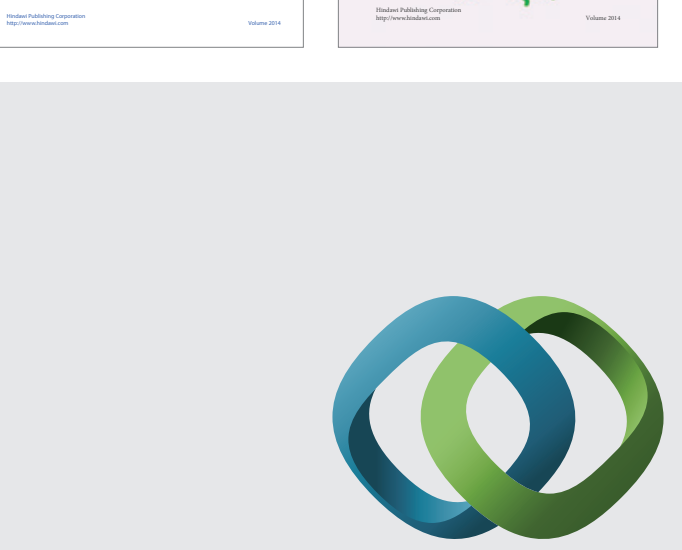

\section{Hindawi}

Submit your manuscripts at

http://www.hindawi.com
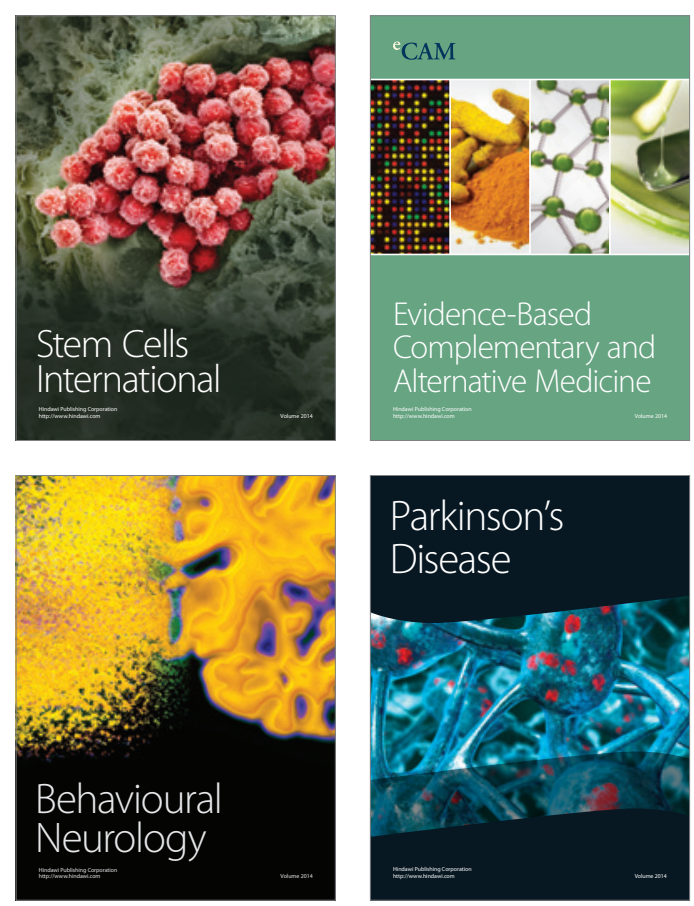

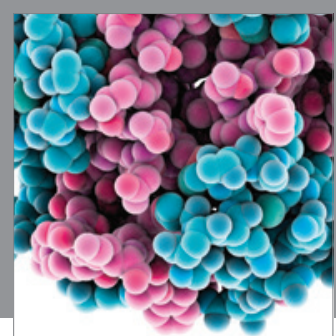

Journal of
Diabetes Research

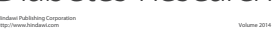

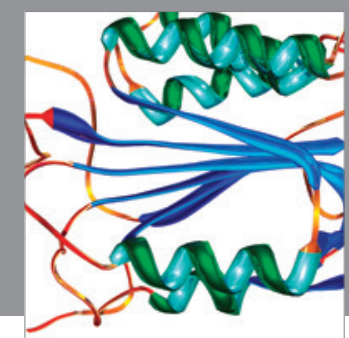

Disease Markers
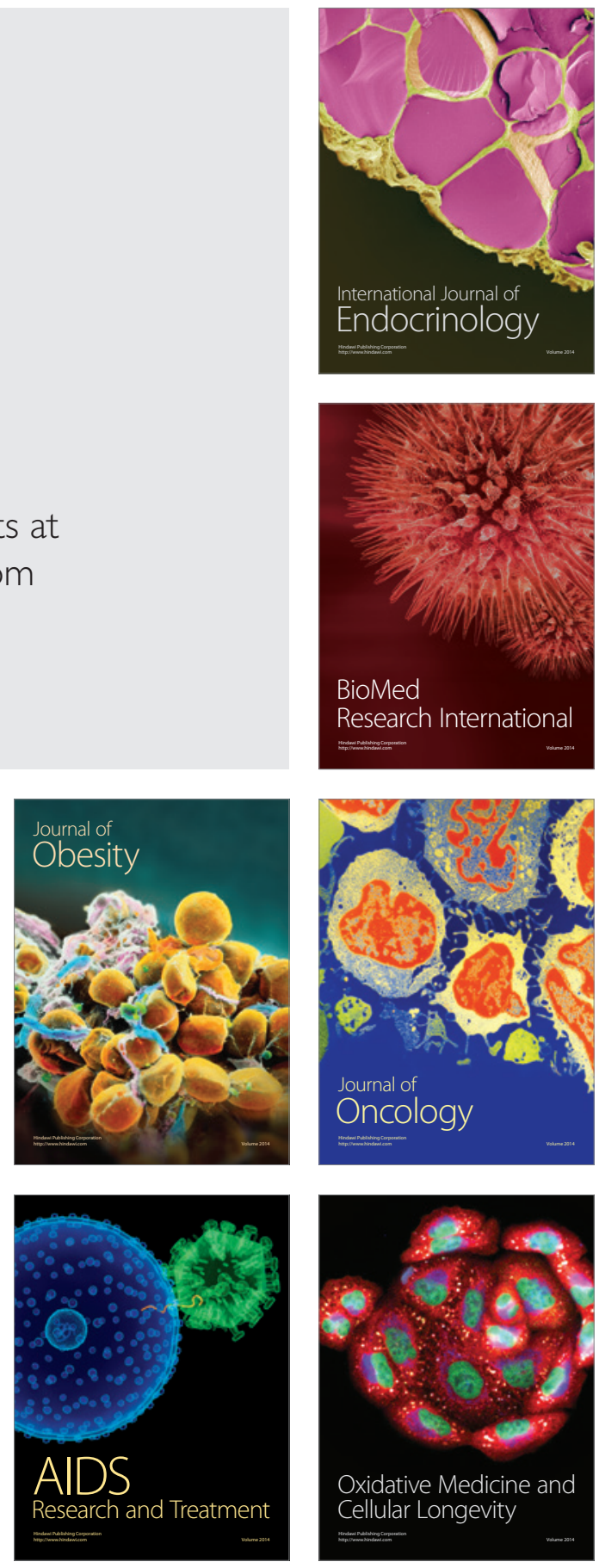